University of Wollongong

Research Online

Faculty of Engineering and Information

Faculty of Engineering and Information

Sciences - Papers: Part A

Sciences

$1-1-2014$

Improved workflow modelling using role activity diagram-based modelling with application to a radiology service case study

Nagesh Shukla

University of Wollongong, nshukla@uow.edu.au

John Keast

University of Warwick

Darek Ceglarek

University of Warwick

Follow this and additional works at: https://ro.uow.edu.au/eispapers

Part of the Engineering Commons, and the Science and Technology Studies Commons

Research Online is the open access institutional repository for the University of Wollongong. For further information contact the UOW Library: research-pubs@uow.edu.au 


\title{
Improved workflow modelling using role activity diagram-based modelling with application to a radiology service case study
}

\author{
Abstract \\ The modelling of complex workflows is an important problem-solving technique within healthcare \\ settings. However, currently most of the workflow models use a simplified flow chart of patient flow \\ obtained using on-site observations, groupbased debates and brainstorming sessions, together with \\ historic patient data. This paper presents a systematic and semi-automatic methodology for knowledge \\ acquisition with detailed process representation using sequential interviews of people in the key roles \\ involved in the service delivery process. The proposed methodology allows the modelling of roles, \\ interactions, actions, and decisions involved in the service delivery process. This approach is based on \\ protocol generation and analysis techniques such as: (i) initial protocol generation based on qualitative \\ interviews of radiology staff, (ii) extraction of key features of the service delivery process, (iii) discovering \\ the relationships among the key features extracted, and, (iv) a graphical representation of the final \\ structured model of the service delivery process. The methodology is demonstrated through a case study \\ of a magnetic resonance (MR) scanning service-delivery process in the radiology department of a large \\ hospital. A set of guidelines is also presented in this paper to visually analyse the resulting process model \\ for identifying process vulnerabilities. A comparative analysis of different workflow models is also \\ conducted.
}

\section{Keywords}

case, role, study, service, improved, workflow, radiology, application, diagram, modelling, activity

\section{Disciplines}

Engineering | Science and Technology Studies

\section{Publication Details}

Shukla, N., Keast, J. \& Ceglarek, D. (2014). Improved workflow modelling using role activity diagram-based modelling with application to a radiology service case study. Computer Methods and Programs in Biomedicine, vol 116, 3, pp: 274-298 


\section{Accepted Manuscript}

Title: Improved Workflow Modelling using Role Activity Diagram-based Modelling with Application to a Radiology Service Case Study

Author: Nagesh Shukla John E. Keast Darek Ceglarek

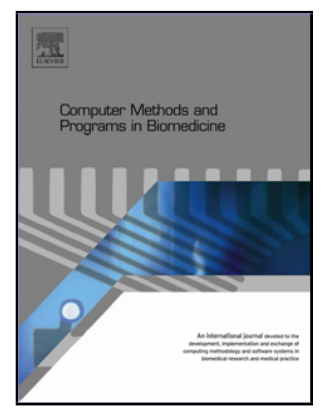

PII: S0169-2607(14)00203-X

DOI: http://dx.doi.org/doi:10.1016/j.cmpb.2014.05.005

Reference: COMM 3802

To appear in: $\quad$ Computer Methods and Programs in Biomedicine

Received date: $\quad 20-10-2013$

Revised date: 28-5-2014

Accepted date: $\quad$ 29-5-2014

Please cite this article as: N. Shukla, J.E. Keast, D. Ceglarek, Improved Workflow Modelling using Role Activity Diagram-based Modelling with Application to a Radiology Service Case Study, Computer Methods and Programs in Biomedicine (2014), http://dx.doi.org/10.1016/j.cmpb.2014.05.005

This is a PDF file of an unedited manuscript that has been accepted for publication. As a service to our customers we are providing this early version of the manuscript. The manuscript will undergo copyediting, typesetting, and review of the resulting proof before it is published in its final form. Please note that during the production process errors may be discovered which could affect the content, and all legal disclaimers that apply to the journal pertain. 


\title{
Improved Workflow Modelling using Role Activity Diagram -based Modelling with Application to a Radiology Service Case Study
}

\author{
Nagesh Shukla $^{1,2}$, John E. Keast ${ }^{1}$, Darek Ceglarek ${ }^{1,3}$ \\ ${ }^{1}$ The Digital Laboratory, WMG, University of Warwick, Coventry, CV4 7AL, UK \\ ${ }^{2}$ SMART Infrastructure Facility, University of Wollongong, NSW, 2522 Australia \\ ${ }^{3}$ Department of Industrial \& Systems Engineering, University of Wisconsin, Madison, WI 53706, USA
}

Abstract: The modelling of complex workflows is an important problem-solving technique within healthcare settings. However, currently most of the workflow models use a simplified flow chart of patient flow obtained using on-site observations, groupbased debates and brainstorming sessions, together with historic patient data. This paper presents a systematic and semi-automatic methodology for knowledge acquisition with detailed process representation using sequential interviews of people in the key roles involved in the service delivery process. The proposed methodology allows the modelling of roles, interactions, actions, and decisions involved in the service delivery process. This approach is based on protocol generation and analysis techniques such as: (i) initial protocol generation based on qualitative interviews of radiology staff, (ii) extraction of key features of the service delivery process, (iii) discovering the relationships among the key features extracted, and, (iv) a graphical representation of the final structured model of the service delivery process. The methodology is demonstrated through a case study of a magnetic resonance (MR) scanning service-delivery process in the radiology department of a large hospital. A set of guidelines is also presented in this paper to visually analyse the resulting process model for identifying process vulnerabilities. A comparative analysis of different workflow models is also conducted.

\section{INTRODUCTION}

Workflow modelling of hospital processes is increasingly seen as a significant step in improving their service delivery system [1].The development of workflow models in hospitals is a challenging task due to the complexity of the knowledge necessary in order to represent information flow, relations, interactions and collaborations occurring in the service delivery process. In general, service delivery processes in hospitals are, to a large extent, unstructured. This is because it is largely dependent on patient outcomes along the way and care must be patient-specific. An effective workflow model will help improve process efficiency by tackling such problems as bottleneck analysis, process waste identification, capacity management, and decision making processes.

While service delivery process improvement is now often seen as key to efficient healthcare services, to date, there have been few process improvement studies. The traditional knowledge acquisition approaches in modelling the service delivery process has relied primarily on group-based debates such as staff workshops. The information gathered by process improvement analysis is mainly in the form of manual notes prepared during discussion which are then used in making high level process maps. This approach lacks the ability to represent the detailed steps required for improvement as important details from the workshop discussions can be missed 
when taking manual notes. Therefore, an approach which can reliably capture highly detailed information about process steps is required.

Workflow modelling based on a role activity diagram (RAD) is employed in this paper together with an information gathering and aggregation approach to effectively model service delivery process. The models based on RAD provide greater understanding of the decisions clinicians make about the care of their patients [2]. The development of RAD-based models helps to highlight process issues which may otherwise remain hidden, resulting in an inefficient/ineffective care delivery process. Current approaches such as group-based debates, brainstorming and workshops are the major mechanisms utilized by qualitative modelling researchers in soft operations research [3-7] and for process mapping/modelling [8,9] . These approaches have a number of limitations. They are time-consuming because they are done manually and if the information is gathered and discussed in a group, power relationships may influence the results. Therefore, a better and more systematic approach is needed. Hence, an innovative methodology is proposed in this paper, one which allows systematic information gathering and aggregation of details of the process into a single structured RAD model. The nature and extent of the details required depends on the specific situation. The general, top-level management requires a rather coarsegrained process description as they want to gain an overview of the process. On the other hand, process improvement analysts/clinicians will prefer a fine-grained process model. Figure 1 illustrates the difference between the current literature and the methodology proposed in this paper. The traditional process mapping techniques rely largely on the manual notes of discussion workshops to visualise the high level process flow. However, the proposed methodology involves a semi-automated step (based on software tools presented in Section 4) to reliably and efficiently capture procedural knowledge before final visualisation based on RADs.

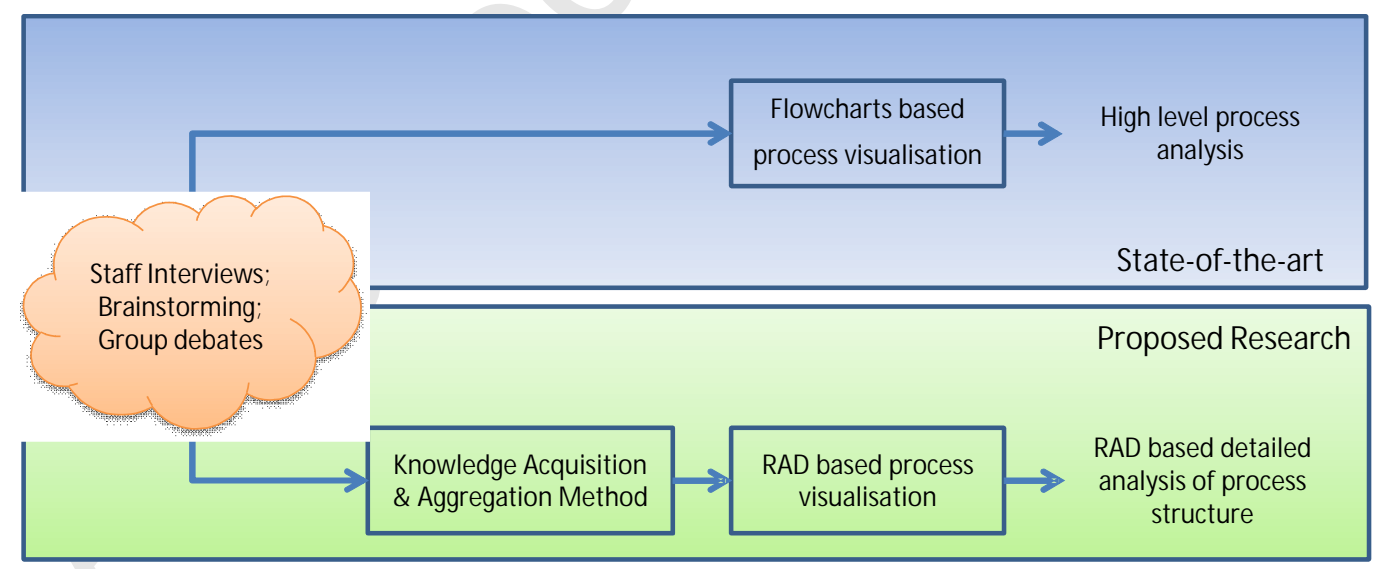

Figure 1: Conceptual representation of the Proposed Methodology

The RAD- based model of healthcare processes is useful for clinicians to see the actual state of the current workflow in the hospital. This helps clinicians to improve decisions regarding patient care, where a high level view of the process is not sufficient. Clinicians must also be provided with the detailed process information to understand the interactions and relations. This will help them to review the process models and formulate their own improvement strategies.

The concepts proposed in the RAD-based methodology is complementary to the existing or ongoing data analysis techniques that seek to identify factors that lead to inefficiency in the healthcare process. In recent years, 'lean' healthcare, a approach 
aimed at providing improvements in healthcare systems, has received much attention [9]. These methods have been used for analysing patient care from start to finish, and highlighting process problems such as process errors, work duplication, waiting/delays, information unavailability, and so on; based on the analysis of tasktime which adds value as opposed to that which does not. When modelling service delivery system, these approaches analyse the most common process followed, but modelling the most standard process is only useful when the service unit has only one way of performing activities. Such systematic and controlled processes are predominant in the manufacturing sector. The lean approaches were intended for improving sequential shop floor manufacturing processes. Hospital departments, however, are fast-paced and characterized by uncertainties. Hence, using the value stream maps (VSMs) of the lean approaches tends to become too complex to accurately model healthcare service delivery due to the presence of large variations in the process steps. Therefore, a systematic approach to model and understand detailed healthcare process model subcomponents is proposed in this paper.

Another approach used to enhance operational efficiency for healthcare organizations is based on data intensive methods such as clustering, classification based on stochastic trees, and prediction based on neural networks. These techniques enable decision makers to identify patterns in clinical claims and activity-based historical data, to better identify and understand the explanatory relationships between variables that describe the operational processes [10-12]. The results of these data analytics are used to inform the decision makers about the relationship between process variables and operational performance. The major limitations of these approaches arise when there is unavailability of quantitative process data to model such systems. In addition, the data analysis model of the service delivery process, when developed with an adequate amount of quantitative data, will only highlight bottlenecks such as long patient queues for scanning, etc. However, detailed process level information is needed to identify the causes of such bottlenecks. Thus, a complete analysis of bottlenecks requires a detailed process map.

Another method used in the area of process improvements is quantitative discrete event simulation models. These models rely on simplified qualitative models such as flowcharts to represent patient flow and historical process data [13-18]. However, qualitative models such as flowcharts (with high level process visualisation) lack the ability to represent complex process relations and interactions between clinical staff, equipment and patients. This leads to incomplete and unrealistic simulation results. Therefore, this paper will also enhance the simulation modelling-based research studies by proposing an innovative information gathering method together with a detailed RAD-based process representation.

The main contributions of the proposed methodology are: the development of a systematic information gathering and aggregation methodology based on staff interviews, the use of RAD-based process models for representing information aggregated from staff interviews, the analysis of sensitive RAD structures for process problem identification and the application of the proposed methodology to a real case study from the radiology department of a large hospital.

The rest of the paper is arranged as follows. In the next section, the literature on service delivery process modelling and improvement is briefly reviewed. Section 3 details the background of the role activity diagram (RAD) and proposed approach for efficient RAD model generation based on semi-structured interviews of the hospital staff. In Section 4, the development of software tools for RAD model generation and workflow analysis is detailed. Section 5 discusses a case study of MR scanning 
workflow process at the radiology department of one large UK hospital. Section 6 details the comparative analysis of the proposed methodology with traditional approaches. Section 7 provides examples of the application of process improvement suggestions in the MR scanning process. Finally, the conclusion and comments are presented in Section 8.

\section{LITERATURE REVIEW}

The initial step for improving the service delivery process is to acquire thorough knowledge of how things are done [19]. This information is complex and qualitative in nature. Traditionally, procedural information in hospitals comes from IT systems, manual records maintained by clinical staff, clinician workshops, group debates, time and motion studies and subject matter experts [8, 20-22]. Information derived from these sources is used to build flow chart-based process models [8], data flow diagrams [23] for analysis and improvement. However, modelling a complex service delivery process based on discussions with hospital staff involved in these processes can be difficult. This is partly due to the fact that some of the important information about the service can be missed during discussions with staff thereby resulting in incomplete data. Therefore, it is necessary to have a rigorous methodology for the effective gathering and handling of qualitative data in order to represent the process [24].

Several studies have explored models such as flowcharts [8], data flow diagrams [23], integrated definition for function modelling (IDEF) [25] and value stream mapping [9] to examine the service delivery process in order to improve efficiency, analyse clinical information systems Recently, Reijers and Mendling [26] have studied the evaluation of various realistic process models for information system development. Sun, et al., [27] have used a process mining method to analyse the distributed execution of a fragmented workflow. McInnes, et al., [28] define formal syntax and semantics for functional flow block diagrams for system analysis. The details of the most commonly used workflow modelling techniques and their suitability for modelling healthcare processes are discussed in the following paragraphs.

Table 1: Classification of process modelling methods for process redesign in healthcare

\begin{tabular}{|c|c|c|c|c|c|}
\hline Methods Capability & $\begin{array}{l}\text { Information } \\
\text { Flow }\end{array}$ & $\begin{array}{l}\text { Sequential } \\
\text { Processes }\end{array}$ & $\begin{array}{l}\text { Parallel } \\
\text { Processes }\end{array}$ & $\begin{array}{l}\text { Collaborative } \\
\text { Processes }\end{array}$ & $\begin{array}{l}\text { Capturing \& } \\
\text { representing } \\
\text { procedural data }\end{array}$ \\
\hline DFDs & Yes & No & No & No & No \\
\hline Flowchart & Yes & $\begin{array}{l}\text { Sequential } \\
\text { flow of } \\
\text { actions }\end{array}$ & No & No & No \\
\hline IDEF0 & Yes & Yes & $\begin{array}{l}\text { Not easy to } \\
\text { visualize }\end{array}$ & No & No \\
\hline IDEF3 & Yes & Yes & Yes & No & No \\
\hline VSM & Yes & Yes & Yes & No & No \\
\hline RAD & Yes & Yes & Yes & $\begin{array}{c}\text { Represents } \\
\text { collaboration among } \\
\text { roles } \\
\end{array}$ & No \\
\hline $\begin{array}{c}\text { RAD based } \\
\text { methodology } \\
\text { (Proposed in this paper) }\end{array}$ & Yes & Yes & Yes & $\begin{array}{c}\text { Represents } \\
\text { collaboration among } \\
\text { roles }\end{array}$ & $\begin{array}{l}\text { Yes. Methodology is } \\
\text { proposed in this paper }\end{array}$ \\
\hline
\end{tabular}


Data flow diagrams (DFDs) represent the flow of data within a system and are useful [23]. These models are easily understood and verified. However, DFDs are unable to represent patient care within the process, which is useful for healthcare service delivery process modelling and analysis (see Table 1 for comparisons).

Flow charts are graphical representations of process in the form of a sequence of activities $[8,29]$. The process model based on flow charts represents the process as a sequence of actions and can be easily created with fewer notations. Flow charts have been used as a first step for the simulation modelling of work flows in healthcare in $[13,14]$. Liu et al., [30] have used flow charts to model the process development of RFID-based workflow. However, flowcharts are not able to represent parallel activities and collaborative processes (see Table 1). Flowcharts also tend to become overly large when modelling complex processes and are better used for high level modelling of the process.

The most common integrated definition for function (IDEF) modelling methods are IDEF0 and IDEF3 [31]. IDEF0 represents high level functions of a process illustrating input, output, control, and the mechanism associated with each function. Ohboshia et al. [32] used IDEF0 for modelling and simulating an emergency department. The major limitation associated with IDEF0-based process modelling is that it often tends to be interpreted as a sequence of activities. IDEF3 is used to capture the behavioural aspect of a process. It utilizes two modelling methods: (i) a process flow diagram (PFD) to illustrate the relationships between actions and (ii) an object state transition description (OSTD), which models the allowable states and conditions for state transitions. This means that IDEF3 can describe the process behaviour but are unable to represent collaborative processes involved within this (see Table 1). Modelling based on IDEF3 requires a great deal of data and many partial diagrams when modelling a complex process.

Value stream mapping (VSM), commonly used in hospital improvement projects based on lean or Toyota production system methods, is another approach to model unstructured processes [9]. VSM approaches have the capability to model sequential and parallel processes including information flow within a process. During process analysis using the VSM approach, all the steps within a process are classified as value-adding and non-value-adding steps with the goal of eliminating or reducing non-value-added activities and improve overall process efficiency. VSMs represent the process as high level sequential steps and it has been predominantly utilized to improve processes involving highly repetitive processes with similar tasks. However, in the case of healthcare service delivery processes, there is a great deal of task variation between patients due to their individual conditions as well as resource availability. Hence, using VSM in modelling healthcare service delivery for process redesign tends to become impractical. It is also the case that service delivery =in healthcare is largely a collaborative process (various roles collaborating with each other to deliver patient care), and this is not represented in VSM (see Table 1).

In this paper, a role activity diagram (RAD) is utilized to represent the healthcare service delivery process. RAD provides graphical representation of the unstructured processes based on people in individual roles, their actions, interactions, and decisions [33-34]. Recently, several applications of RAD based methods have been introduced [39-41]. RADs are easy to understand and present a detailed view of the process including sequential, parallel and collaborative processes including scenarios with multiple interactions between roles (see Table 1). Hence, RAD can represent the service delivery process in healthcare better than other methods 
This paper also presents a systematic methodology for information gathering about healthcare processes using sequential interviews with staff playing key roles in the processes and then aggregating this knowledge into a single structured model using role activity diagram (RAD) representations. The methodology gathers the qualitative data about the process from staff interviews, elicits the relevant process related terms/features from interviews, and relates the elicited terms to represent the process based on RAD. Table 1 classifies various process modelling methods in the literature based on their ability to represent the service delivery process and their capability to capture and represent procedural knowledge. The shaded cells of the table represent some of the shortcomings of these methods. RAD-based modelling provides the ability to represent and model unstructured healthcare processes which then can be used for process improvement.

The following section discusses $t$ the details of the qualitative modelling (RADbased) methodology.

\section{QUALITATIVE MODELLING OF THE HEALTHCARE SERVICE DELIVERY PROCESS}

RAD can be defined as a process modelling method originally developed for effectively modelling collaborative processes $[33,34]$. In this study, we employ RAD for modelling a service delivery process of a large hospital. Before any process modelling can be performed, one needs a clear understanding of the fundamental concepts and notations of RAD. Table 2 provides some of the fundamental concepts, general description and examples of their application in a hospital. Table 2 also provides the corresponding graphical representation for each of the RAD concepts utilized to model the service delivery process.

Step 1 of the methodology identifies the scope of the process that is to be modelled together with identifying key roles involved within the process. Step 2 focuses on conducting interviews with staff in key roles and generating interview transcripts. The process-related features and terms are extracted in Step 3. The relationships among the extracted terms are created in Step 4 with the help of various matrices, such as action-type, action-role, interaction-role and others to develop the quantitative base for RAD development. Once relationship matrices are created, the RAD model is graphically represented by following the procedure defined in Step 5. A simple example of a radiology department is used in this section to illustrate each of the steps.

\begin{tabular}{|c|c|c|c|c|}
\hline $\begin{array}{l}\text { STEP 1: } \\
\text { Identification of } \text { key roles and } \\
\text { scope of process modelling }\end{array}$ & $\rightarrow \begin{array}{l}\text { STEP 2: } \\
\text { Interview transcript generation } \\
\text { for RAD development }\end{array}$ & $\rightarrow \begin{array}{l}\text { STEP 3: } \\
\text { Extraction of terms relevant } \\
\text { for } R A D\end{array}$ & $\begin{array}{l}\text { STEP 4: } \\
\text { Building the relationships } \\
\text { among extracted terms }\end{array}$ & $\rightarrow \begin{array}{l}\text { STEP 5: } \\
\text { RAD model generation }\end{array}$ \\
\hline
\end{tabular}

Figure 2: Steps involved in the RAD development

The following subsection describes the formal procedure that is proposed in this paper to model the service delivery process as RAD.

\subsection{Knowledge acquisition for qualitative modelling of healthcare service delivery process}

In this subsection, the qualitative data regarding the service delivery process which is used in next sub-section for RAD- based model generation is discussed. . 


\section{STEP 1: Identification of the key roles and the scope of the process modelling}

One of the main ideas behind improving the efficiency of the service delivery process is to identify and define the scope of that process. Those hospital service delivery processes which are not performing as required against the key performance metrics are identified. . The key members of the radiology staff involved from the beginning to the end of a selected process are chosen for interviewing in the next step.

Table 2: Description of RAD concepts and its graphical representation

\begin{tabular}{|c|c|c|c|c|c|}
\hline S. No. & $\begin{array}{l}\text { RAD } \\
\text { concept }\end{array}$ & $\begin{array}{l}\text { Capability } \\
\text { type }\end{array}$ & General description & $\begin{array}{l}\text { Examples of application } \\
\text { in radiology department }\end{array}$ & $\begin{array}{c}\text { Graphical } \\
\text { notations }\end{array}$ \\
\hline 1. & Role & Collaboration & $\begin{array}{l}\text { A role performs a set of actions in } \\
\text { order to fulfil a particular } \\
\text { responsibility within a process. Roles } \\
\text { are usually performed by an } \\
\text { individual, group of people, IT } \\
\text { system, and machine or equipment. }\end{array}$ & $\begin{array}{l}\text { Clinical doctors, porters, } \\
\text { nurses, technicians }\end{array}$ & \\
\hline 2. & Activity & $\begin{array}{l}\text { Sequential or } \\
\text { Parallel } \\
\text { process }\end{array}$ & $\begin{array}{l}\text { An activity is a unit of work } \\
\text { performed by a particular role. }\end{array}$ & $\begin{array}{l}\text { Move patient to changing } \\
\text { room, position patient on } \\
\text { table }\end{array}$ & \\
\hline 3. & Interaction & $\begin{array}{l}\text { Information } \\
\text { flow or } \\
\text { Collaboration }\end{array}$ & $\begin{array}{l}\text { People collaborate in order to achieve } \\
\text { the service delivery process } \\
\text { objective. }\end{array}$ & $\begin{array}{l}\text { Pass } X \text {-ray of the patient } \\
\text { from technician to } \\
\text { radiology doctors }\end{array}$ & \\
\hline 4. & $\begin{array}{l}\text { Part } \\
\text { refinement }\end{array}$ & $\begin{array}{l}\text { Parallel } \\
\text { Process }\end{array}$ & $\begin{array}{l}\text { The part refinement symbol refers to } \\
\text { the work done simultaneously by a } \\
\text { role. This is graphically represented } \\
\text { by single thread of activity dividing } \\
\text { into parallel threads within a role. }\end{array}$ & $\begin{array}{l}\text { Patient booking, and } \\
\text { printing patient non } \\
\text { attendance letters }\end{array}$ & \\
\hline 5. & $\begin{array}{l}\text { Case } \\
\text { refinement }\end{array}$ & $\begin{array}{l}\text { Sequential } \\
\text { Process }\end{array}$ & $\begin{array}{l}\text { The case refinement is used to } \\
\text { represent decision question and } \\
\text { possible outcomes. }\end{array}$ & $\begin{array}{c}\text { Decision question: Does } \\
\text { patient require contrast } \\
\text { injection? } \\
\text { Outcome: Yes, or No. }\end{array}$ & \\
\hline 6. & Trigger & $\begin{array}{l}\text { Sequential } \\
\text { Process }\end{array}$ & $\begin{array}{l}\text { Trigger is an event that starts the } \\
\text { activity thread. }\end{array}$ & $\begin{array}{l}\text { Arrival of patient scan } \\
\text { request }\end{array}$ & \\
\hline 7. & State & $\begin{array}{l}\text { State } \\
\text { transitions }\end{array}$ & $\begin{array}{l}\text { A state describes what is true either } \\
\text { before or after some actions (actions } \\
\text { can encompass activities, interactions, } \\
\text { and encapsulated processes). }\end{array}$ & $\begin{array}{c}\text { Scan is finished, patient } \\
\text { can have scan }\end{array}$ & \\
\hline 8. & Loop & Repetition & $\begin{array}{l}\text { The loop symbol allows a part of a } \\
\text { process to be repeated. The iteration } \\
\text { starts at the end of an activity and } \\
\text { goes back to a prior activity. }\end{array}$ & $\begin{array}{l}\text { Multiple attempt to give } \\
\text { injection }\end{array}$ & \\
\hline 9. & Replication & Repetition & $\begin{array}{l}\text { This symbol is used to define the } \\
\text { nature of the repetition of certain } \\
\text { activities in the process. }\end{array}$ & $\begin{array}{l}\text { Maximum two repeats in } \\
\text { giving injections }\end{array}$ & \\
\hline 10. & $\begin{array}{l}\text { Encapsulate } \\
\text { d process }\end{array}$ & Hierarchy & $\begin{array}{l}\text { The encapsulated process allows us to } \\
\text { represent complex sub-processes as a } \\
\text { separate diagram and indicating it as a } \\
\text { symbol in the main diagram }\end{array}$ & Perform patient scanning & \\
\hline 11. & Start role & Other & $\begin{array}{l}\text { This symbol is used to initiate a } \\
\text { transient role in the main diagram. }\end{array}$ & $\begin{array}{l}\text { Patient scan request } \\
\text { vetting by radiology } \\
\text { doctors }\end{array}$ & \\
\hline 12. & Other work & Other & $\begin{array}{l}\text { It represents the other work that does } \\
\text { not relate to the main process } \\
\text { performed by the role. }\end{array}$ & & \\
\hline 13. & Stop & Other & $\begin{array}{l}\text { This symbol marks the end of one or } \\
\text { more threads to indicate the end point } \\
\text { of the process. }\end{array}$ & & \\
\hline
\end{tabular}




\section{STEP 2: Interview transcript generation for RAD development}

Semi-structured interviews are conducted with staff in the key roles identified in Step 1. These interviews help to gather information about staff roles and responsibilities within the selected service delivery process. The interviews are recorded and subsequently transcribed. Section 5 outlines the selection of the members of staff who were interviewed for our case study. Following is a briefly transcribed interview of the radiology nurse to illustrate the methodology :

\section{Example 1:}

Interview Transcript: "Radiology nurse will go to the patient waiting in reception, then go through a questionnaire with every patient, this is done to identify whether the patient has metal on them or not. If no metal is found, patient is allowed to change for whatever sort of scan they are having, otherwise failed consent procedure is used."

\subsection{Knowledge aggregation for quantitative model generation}

In this subsection, the qualitative data, gathered in subsection 3.1, is used for developing an RAD model of the service delivery process.

\section{STEP 3: Extraction of terms relevant for RAD}

To construct the RAD of the radiology service delivery process, it is necessary to have information about the roles involved, the activities performed, the responsibilities of staff and interactions among them, the decisions made, the resource utilized, and other related issues. This step involves the identification and extraction of relevant process elements for RAD development. The process improvement expert involved in the staff interviews (in step 2) identifies terms in the transcript which are relevant to RAD development. The procedural terms that are extracted from the interview transcripts are: roles, actions, decision outcomes, resources, interactions between roles, and their descriptions. Once the expert has identified these terms, these are then automatically extracted and stored in the form of matrices which are used in step 4 for relationship matching. The main relationships are between: an action and its types, actions and roles, interaction and roles, actions and resources, and descriptions of roles, resources, and actions. The terms extracted from the interview transcript of Example 1 are as follows:

$\langle$ Radiology nurse $\rangle$, <go to the patient $\rangle$, <patient $\rangle$, <go through a questionnaire $\rangle$, $<$ whether the patient has metal on them $\rangle$, <allowed to change $\rangle$, <failed consenting procedure is used>

Where, $<$ term $>$ indicates the extracted terms from the interview transcript of Example 1. These concepts are utilized in the next step for relationship building.

\section{STEP 4: Building the relationships among extracted terms}

The extracted terms are connected with each other in order to construct an RAD of the service delivery process under consideration. Relationship matrices are constructed to relate the extracted terms. This provides the quantitative base for RAD development. The main relationship matrices developed are: 
A. Action-Type matrix (AT): This relates the extracted terms with the RAD notations such as activity, state, trigger, start role, case refinement, part refinement and encapsulated process. The RAD notations used in this paper and related description are given in Table 2. In this matrix, the rows represent the extracted terms defined as actions, and the columns represent the RAD notations. The value of the matrix attribute is 1 if the relation exists between the corresponding row and column, otherwise it is set to 0 . Table 3 represents the simple case of AT matrix where the extracted actions are denoted as 'Action 1, Action 2,..., Action N'. Mathematically,

$$
[A T]_{i j}=\left\{\begin{array}{cc}
1 & \text { if Action } i \text { is of type } j \\
0 & \text { otherwise }
\end{array}\right.
$$

Table 3: Action-type matrix relating the actions to their types.

\begin{tabular}{|c|c|c|c|c|c|c|c|}
\hline $\begin{array}{c}\text { Action- } \\
\text { Type }\end{array}$ & Activity & State & Trigger & $\begin{array}{c}\text { Start } \\
\text { Role }\end{array}$ & $\begin{array}{c}\text { Case } \\
\text { refinement }\end{array}$ & $\begin{array}{c}\text { Part } \\
\text { refinement }\end{array}$ & $\begin{array}{c}\text { Encapsulated } \\
\text { process }\end{array}$ \\
\hline Action 1 & 0 & 0 & 1 & 0 & 0 & 0 & 0 \\
\hline Action 2 & 1 & 0 & 0 & 0 & 0 & 0 & 0 \\
\hline$:$ & $:$ & $:$ & $:$ & $:$ & $:$ & $:$ & $:$ \\
\hline Action $N$ & 1 & 0 & 0 & 0 & 0 & 0 & 0 \\
\hline
\end{tabular}

The AT matrix for Example 1 is illustrated in Table 4.

Table 4: Action-type matrix for the Example 1

\begin{tabular}{|c|c|c|c|c|c|c|c|}
\hline Action-Type & Activity & State & Trigger & $\begin{array}{c}\text { Start } \\
\text { Role }\end{array}$ & $\begin{array}{c}\text { Case } \\
\text { refinement }\end{array}$ & $\begin{array}{c}\text { Part } \\
\text { refinement }\end{array}$ & $\begin{array}{c}\text { Encapsulated } \\
\text { process }\end{array}$ \\
\hline <go to the patient> & 1 & 0 & 0 & 0 & 0 & 0 & 0 \\
\hline $\begin{array}{c}\text { <hether the patient has } \\
\text { metal on them> }\end{array}$ & 0 & 0 & 0 & 0 & 1 & 0 & 0 \\
\hline <allowed to change > & 1 & 0 & 0 & 0 & 0 & 0 & 0 \\
\hline $\begin{array}{c}\text { <failed consenting } \\
\text { procedure is used }>\end{array}$ & 0 & 0 & 0 & 0 & 0 & 0 & 1 \\
\hline
\end{tabular}

B. Action-Role matrix (AR): This matrix relates the extracted actions with the respective roles. It establishes the relationship of action to role, which will be helpful in drawing up the process diagrams based on the concepts of the RAD. Table 5.a shows the AR matrix where the row represents the extracted terms and the column represents the roles. Table 4 relates ' $N$ ' actions with ' $R$ ' roles. Mathematically,

$$
[A R]_{i j}=\left\{\begin{array}{cc}
1 & \text { if Action } i \text { belongs to } j^{\text {th }} \text { role } \\
0 & \text { otherwise }
\end{array}\right.
$$

The AR matrix for extracted items of Example 1 is illustrated with the help of Table 5.b.

Table 5: (a) Generic Action-role matrix; (b) Action-role matrix for Example 1

\begin{tabular}{|c|c|c|}
\hline Action-Role & $\begin{array}{l}\langle\text { Radiology } \\
\text { nurse }>\end{array}$ & $\langle$ patient $\rangle$ \\
\hline$\langle$ go to the patient $\rangle$ & 1 & 0 \\
\hline $\begin{array}{c}\langle\text { whether the patient has metal on } \\
\text { them }>\end{array}$ & 0 & 1 \\
\hline$\langle$ allowed to change $>$ & 0 & 1 \\
\hline $\begin{array}{c}\langle\text { failed consenting procedure is } \\
\text { used }\rangle\end{array}$ & 0 & 1 \\
\hline
\end{tabular}

\begin{tabular}{|c|c|c|c|c|}
\hline $\begin{array}{c}\text { Action- } \\
\text { Role }\end{array}$ & $\begin{array}{c}\text { Role } \\
1\end{array}$ & $\begin{array}{c}\text { Role } \\
2\end{array}$ & $\cdots$ & $\begin{array}{c}\text { Role } \\
\text { 'R' }\end{array}$ \\
\hline Action 1 & 0 & 1 & $\ldots$ & 0 \\
\hline Action 2 & 1 & 0 & $\cdots$ & 0 \\
\hline$:$ & $:$ & $:$ & $:$ & $:$ \\
\hline Action $N$ & 1 & 0 & $\ldots$ & 0 \\
\hline
\end{tabular}

C. Interaction-Roles matrix (IR): This relates the interactions between two or more roles. The rows in the matrix represent the interactions and the columns 
represent the roles. Table 6.a denotes the format of the IR matrix which is constructed with the help of the interview transcripts. Interactions between roles are necessary when performing collaborative tasks and the information about all the interactions can be obtained by carefully extracting the relevant terms from the interview transcripts.

Mathematically, the attribute of the matrix IR is defined as:

$$
[I R]_{i j}= \begin{cases}1 & \text { if } j^{\text {th }} \text { role is a driver of } i^{\text {th }} \text { Interaction } \\ 2 & \text { if } j^{\text {th }} \text { role is a reciever of } i^{\text {th }} \text { Interaction } \\ 0 & \text { Otherwise }\end{cases}
$$

The IR matrix for extracted items of Example 1 is illustrated with the help of Table 6.b.

Table 6: (a) Generic Interaction-role matrix; (b) Interaction-role matrix for Example 1

\begin{tabular}{|c|c|c|c|c|c|}
\hline $\begin{array}{c}\text { Interaction- } \\
\text { Role }\end{array}$ & $\begin{array}{c}\text { Role } \\
1\end{array}$ & $\begin{array}{c}\text { Role } \\
2\end{array}$ & $\begin{array}{c}\text { Role } \\
3\end{array}$ & $\cdots$ & $\begin{array}{c}\text { Role } \\
\text { ' } R\end{array}$ \\
\hline Interaction 1 & 0 & 2 & 1 & $\ldots$ & 1 \\
\hline Interaction 2 & 1 & 0 & 0 & $\ldots$ & 0 \\
\hline$:$ & $:$ & $:$ & $:$ & $:$ & $:$ \\
\hline Interaction I & 1 & 0 & 1 & $\ldots$ & 0 \\
\hline
\end{tabular}

\begin{tabular}{|c|c|c|}
\hline Interaction-Role & $\begin{array}{c}\langle\text { Radiology } \\
\text { nurse }\rangle\end{array}$ & $\langle$ patient $\rangle$ \\
\hline $\begin{array}{c}\langle\text { go through a } \\
\text { questionnaire }\rangle\end{array}$ & 1 & 1 \\
\hline
\end{tabular}

D. Action-Resource matrix (AS): This represents the relationship between the action performed and the useful resources consumed. The rows and columns in the AS matrix represent the activities and resources. Table 7 represents the AS matrix for relating activities with their resources.

$$
[A S]_{i j}=\left\{\begin{array}{lc}
1 & \text { if Action } i \text { involves Resource } j \\
0 & \text { otherwise }
\end{array}\right.
$$

Table 7: Matrix relating activities with their resources

\begin{tabular}{|c|c|c|c|c|c|}
\hline $\begin{array}{c}\text { Activity- } \\
\text { Resource }\end{array}$ & Resource 1 & Resource 2 & Resource 3 & $\ldots$ & Resource ' $S$ ' \\
\hline Action 1 & 0 & 0 & 1 & $\ldots$ & 1 \\
\hline Action 2 & 1 & 0 & 0 & $\ldots$ & 0 \\
\hline$:$ & $:$ & $:$ & $:$ & $:$ & $:$ \\
\hline Action N & 1 & 0 & 1 & $\ldots$ & 0 \\
\hline
\end{tabular}

The AS matrix for Example 1 does not exist as no resource has been extracted from the interview transcript in Step 2.

E. Action-Description matrix, Role-Description matrix, Resource-Description matrix: These matrices are fairly straightforward and are used to retain the knowledge about the terms extracted from the interview transcripts. The rows represent actions, roles, and resources, while the columns represent the description. The matrix attribute value is 1 if corresponding activity or role or resource relates to the description defined for the column; otherwise the attribute value is set to 0 .

The abovementioned matrices form the quantitative data structure that is used to develop the RAD model in the radiology department.

\section{STEP 5: RAD model generation}


The matrices defined in Step 4 are used to construct the RAD of the service delivery process. In order to represent the RAD graphically, it is necessary to develop an RAD concept library ( $\mathbf{T})$ which constitutes the RAD graphical notations (illustrated in Table 2). The RAD concept library $\mathbf{T}$ is defined as:

$$
\mathbf{T}=\left(t_{1}, t_{2}, t_{3} \cdots t_{13}\right)
$$

Each of the elements in $\mathbf{T}$ signifies a distinct notation in RAD and there are in total 13 notations. Role symbol is defined by $t_{1}$, activity symbol is denoted by $t_{2}$, and interaction is denoted by $t_{3}$, and so on until loop is denoted by $t_{13}$. From Step $3, N$ actions, $R$ roles, and $I$ interactions are identified and this is used to develop a procedure for the development of the RAD which is as follows:

1: Set $r=1, i=1$, and $j=1$.

2: For $r^{\text {th }}$ role, where $r \in(1,2,3, \cdots, R)$

$$
\begin{aligned}
& \text { draw_shape }\left(t_{1}\right) \quad / / \text { drawing the shape of a role } \\
& \text { for } i^{\text {th }} \text { action, where } i \in(1,2,3, \cdots, N)
\end{aligned}
$$$$
\text { if }[A R]_{i r}==1 \text { then }
$$$$
\text { type=action_type }(i) / / \text { get the type of activity }
$$

\section{End If}

$$
\begin{gathered}
\text { draw_shape(type) // draw shape of activity type inside } \\
\text { // role shape }
\end{gathered}
$$

\section{End For}

\section{End For}

3: For $j^{\text {th }}$ interaction, where $j \in(1,2,3, \cdots, I)$

$$
\begin{aligned}
& \text { For } r^{\text {th }} \text { role, where } r \in(1,2,3, \cdots, R) \\
& \text { if }[I R]_{j r}==1 \text { or } 2 \text { then } \\
& \text { draw_shape }\left(t_{2}\right) / / \text { draw interaction shape inside role } \\
& \text { // shape }
\end{aligned}
$$

\section{End If}

\section{End For}

\section{End For}

4: Join all the RAD notations logically based on the interview transcript

5: End

The RAD diagram for Example 1 constructed following the above steps is illustrated in Fig. 3. The term 'failed consenting procedure of used' in Fig. 3, is a subprocess and hence is represented by the encapsulated process symbol.

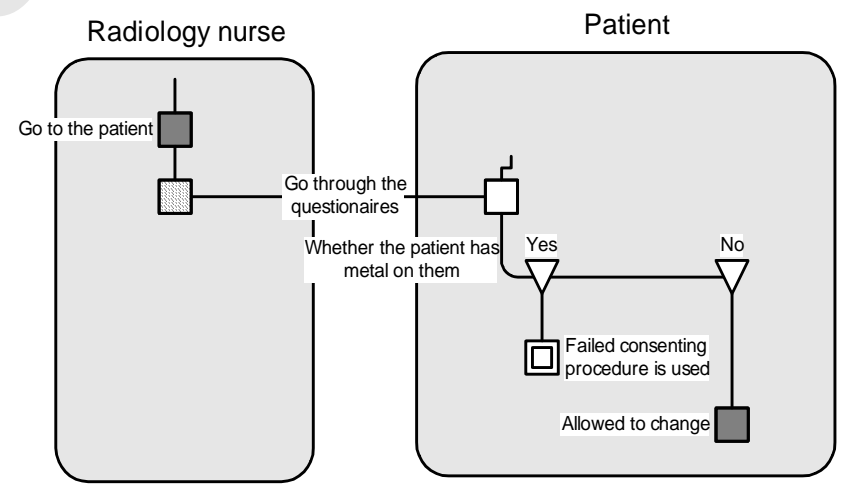

Figure 3: RAD for Example 1 
The RAD of the process is not totally automatic and manual interventions are required to define the sequence of RAD symbols. The resulting RAD models are verified with the help of staff following the 'teach back' method and any inconsistencies or problems are edited and modified manually to reflect the reality. This RAD model can be further examined to conduct time-based analysis. Time-based analysis is beyond the scope of the current study and will be presented in more detail in our future studies. The following section shows the implementation of the proposed methodology by constructing the software tools necessary to model and analyse the RADs.

\section{IMPLEMENTATION OF RAD-BASED QUALITATIVE MODELLING OF THE HEALTHCARE SERVICE DELIVERY PROCESS}

This section details the development of software tools based on RAD modelling for each of the four steps (see Section 3). The following subsections provide information about the software tools developed for each step.

\subsection{Identifying key roles and the scope of the process}

The scope of the process model and key roles are identified manually based on communications with the senior clinician/manager responsible for managing process performance.

\subsection{Interview transcript generation based on Microsoft Word}

The implementation phase starts when all the qualitative interviews of selected radiology staff are recorded on audio tape as our primary protocol generation technique. Interviews are then transcribed into Microsoft Word documents.

\subsection{Software tool for extracting RAD concepts}

We developed a software toolbar (as a Visual Basic Macro) which uses Microsoft Word to extract terms from the transcribed interviews which are relevant for RAD construction (see Fig. 4). Using this tool, the Action Name, Action Description, Role Name, Role Description, Interaction Name, Decision Question, Resource Name and Resource Description can be marked by the process analyst in the Microsoft Word transcript. To collect more information from interviews, we have included new concepts in our software tool such as Glossary Item, Glossary Description, Issue Description, Flow Object, Actor Name, and Organisation Name. These markings are done to extract the relevant terms from the transcripts.

\subsection{Relationship builder interface}

After marking/extracting the relevant terms from the Microsoft Word transcripts, the extracted term is automatically exported into a matrix-based graphical user interface. This user interface allows process the improvement analyst to define the relationships between the extracted terms (see Fig. 5). The matrix-based interface, as shown in Fig. 5, has the same set of matrices that are defined in Step 4. All the matrices defined in Step 4 are included in the relationship builder interface for defining the relationships. The matrix-based interface helps to define relationships between marked terms by entering the attribute values (i.e., 1 or 0 ) of the matrices. 


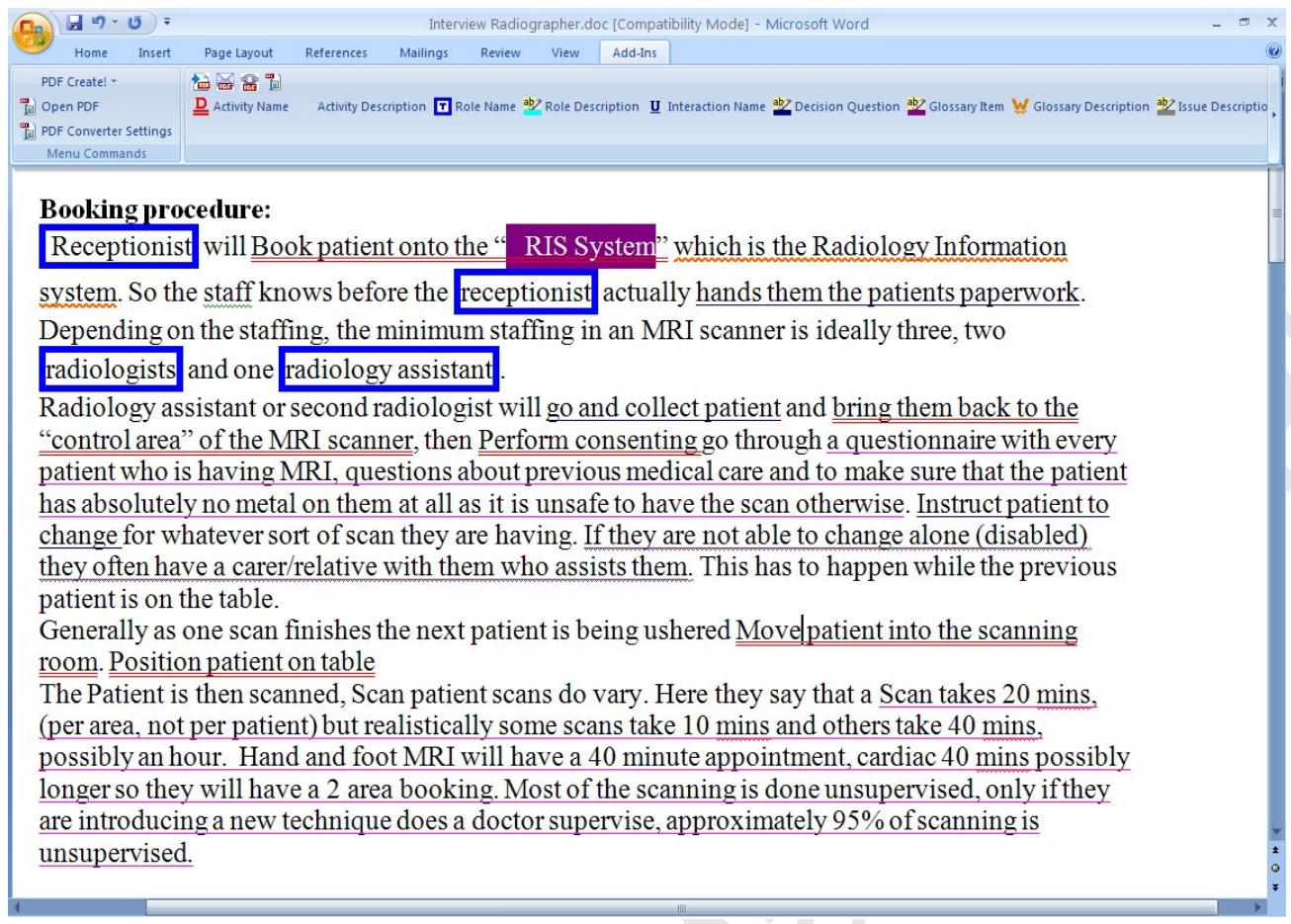

Figure 4: Microsoft Word mark-up tool for marking procedural knowledge concepts

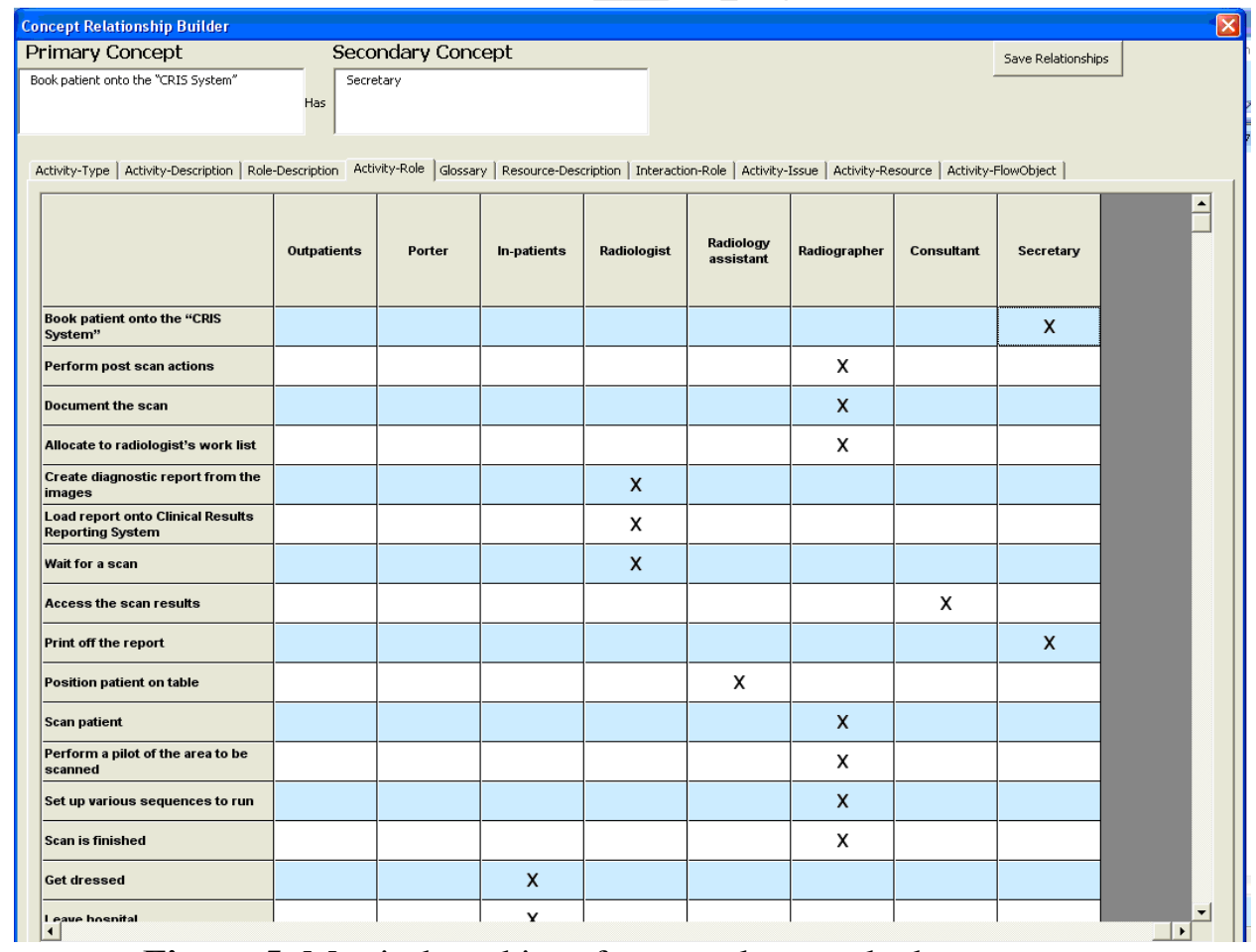

Figure 5: Matrix-based interface to relate marked-up concepts

\subsection{Graphical representation of RAD in MS Visio}

The marked terms and their matrix-based relationships are then exported to Microsoft Visio where an RAD is automatically generated using the RAD shape library (T) in Visio and the algorithm defined in Step 5 (see Fig. 6). The information 
about the strict sequence of the activities may not be present during the interview transcripts, as participants are often unable to describe the activities in strict sequence. However, based upon the interview transcripts, it is possible to create an approximate sequence. The approximate sequence in RAD can be refined by validating it with the selected

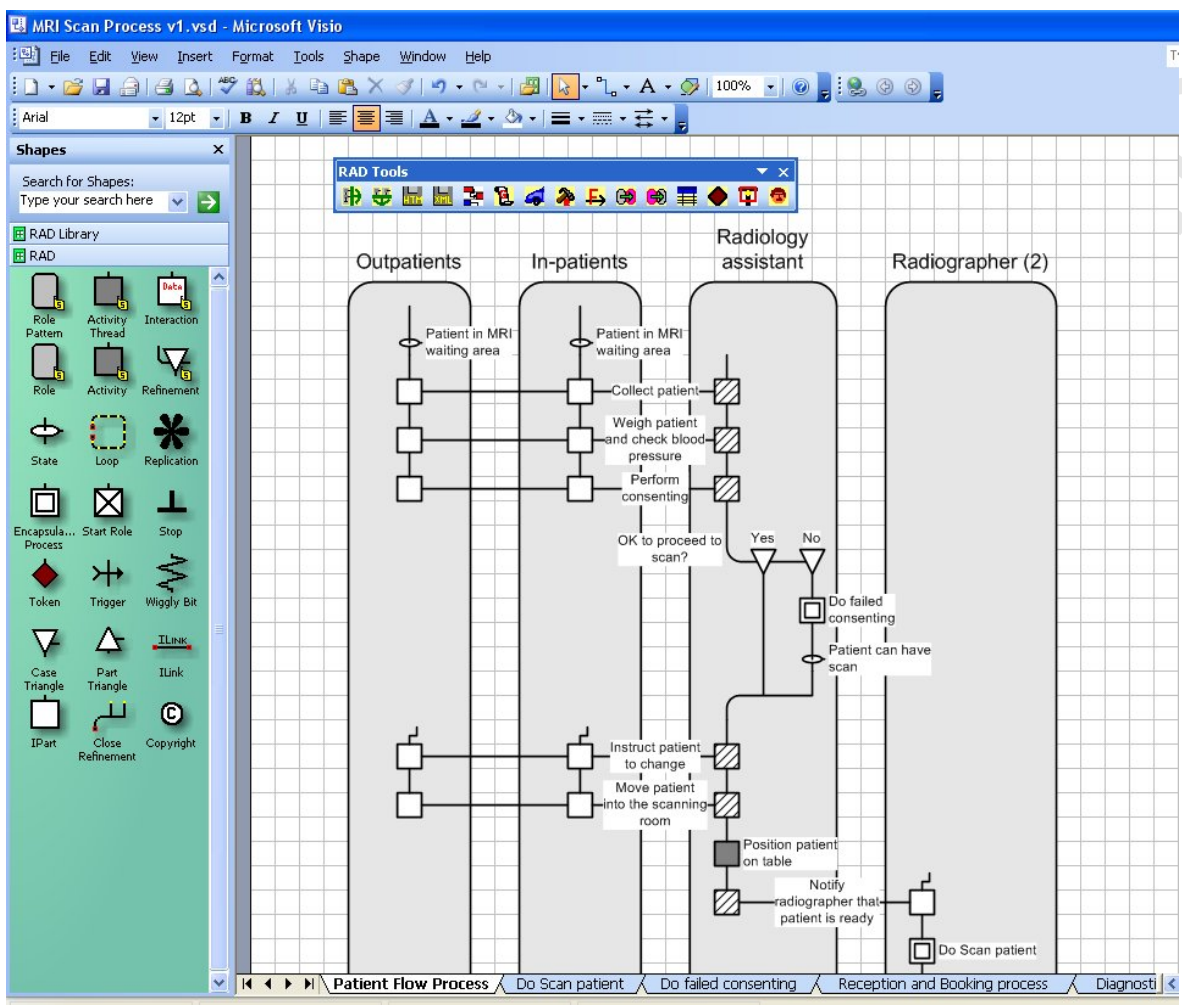

Figure 6: MS Visio- based RAD stencil.

member of staff who was interviewed. Subsequently, new information from key clinicians can also be added manually to the developed RAD to improve the service delivery process model.

The following section shows the application of the proposed RAD-based workflow modelling methodology on the magnetic resonance (MR) scanning process of the radiology department.

\section{CASE STUDY}

The case study involves the MR scanning service in the radiology department at a large hospital in the UK. The radiology unit has three MR scanners to deal with scan requests from different departments in the hospital. Radiographers and radiologists do this with the help of radiology assistants, receptionists, and porters. Each of the MR scanners is assigned two radiographers to scan patients and one radiology assistant to prepare patients for scanning. Several IT systems, including a radiology information system (RIS), a picture archiving and communication system (PACS), and a clinical reporting system (CRS) are used to schedule patient appointments, archive patient scans, and review scan reports. 
The large number of requests for MR scans puts enormous pressure on imaging services. According to nationally recommended patient care guidelines in the UK, no patient should wait more than 18 weeks for their treatment. Imaging services for patients is identified as a major element in the 18 week care pathway. Therefore, the radiology department in the hospital is under tremendous pressure to meet these guidelines.

Specifically, the whole MR patient scanning process can be divided into the patient booking process; the patient arrival process; patient scanning; and the scan review reporting process (see Fig. 7).

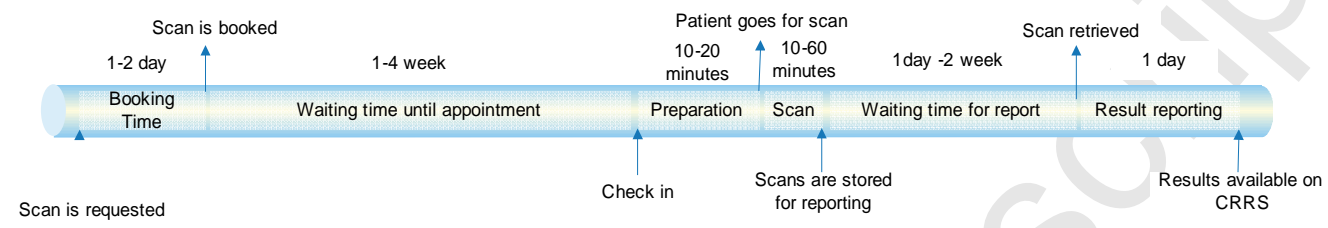

Figure 7: Breakdown of the overall time from outpatient request to results Figure 7 illustrates this breakdown. The MR scanners are expensive for the hospital, and they are required to perform efficiently to meet the rising demand.. Efforts were made to improve the process because of $(i)$ long waiting times from scan request to actual MR scanning date (3-4 weeks for outpatients); (ii) a low average utilization rate of the MR scanners ( 40-50\%); and, (iii) suggestions that other forms of radiology such as CT (computed tomography), nuclear medicine, X-ray, and ultrasound could be substituted.. The RAD methodology is applied to model the MR scanning process. The subsections below detail the application of the proposed methodology for the RAD- based modelling of the MR scanning process.

\section{Knowledge acquisition for RAD modelling of the MR scanning process}

\subsection{Identifying key roles in the MR scanning process}

Initially, the list of roles involved in the MR scanning process was elicited by interviewing the radiology manager. The key roles, such as the receptionist at reception, the receptionist in the booking department, identified as Receptionist and Booking Department in the RAD model) the radiology assistant, the radiographer, and the radiologist, are all involved in the process.. These receptionists are

\subsection{Interview transcript generation for RAD development}

The face-to-face 30- minute interviews with staff in the key roles, identified in subsection 5.1, were conducted in the radiology department on one day by project staff. Each selected member of the radiology staff was asked to detail their involvement in the MR scanning process. The interviews were recorded using a digital recorder DS-40 from Olympus. After recording, the audio files were transcribed into Microsoft Word (2003).

\section{Knowledge aggregation for RAD modelling of the MR scanning process}

\subsection{Extracting RAD concepts based on a software tool}

The Microsoft Word transcripts were marked with RAD concepts such as actions, interactions, roles, resources, their descriptions, glossary terms and related issues (see Table 2). Marking was done using the protocol editor software tool that is developed as a macro for Microsoft Word (2003). 


\subsection{Building relationship matrices based on builder interface}

The extracted concepts by the protocol editor were related to each other using a matrix-based relationship builder interface (defined in Section 4.4). The relationships are defined based on the knowledge obtained from the qualitative interviews with radiology staff. Appendix 1.2 illustrates the relationship matrices AT, AR, and IR in the relationship builder interface that relate the marked concepts from interviews.

\subsection{Graphically representing RAD in MS Visio}

Once the marked concepts were related, the relationships were exported to Microsoft Visio, which has the RAD stencil, to construct the RAD of the MR scanning process. In order to represent the RAD model clearly, the whole RAD model is divided into four RAD models: patient booking, patient arrival, patient scanning, and diagnostic reporting process. These models were verified with the help of the 'teach back' approach, where these models were shown to the same members of staff who were interviewed for editing inconsistencies. This resulted in the development of verified RAD representation of the MR scanning process. The logic flow between these RADs is illustrated in Fig. 8. Below is the discussion of the RAD model developed for patient booking, patient arrival, patient scanning, and diagnostic reporting of the MR scan process.

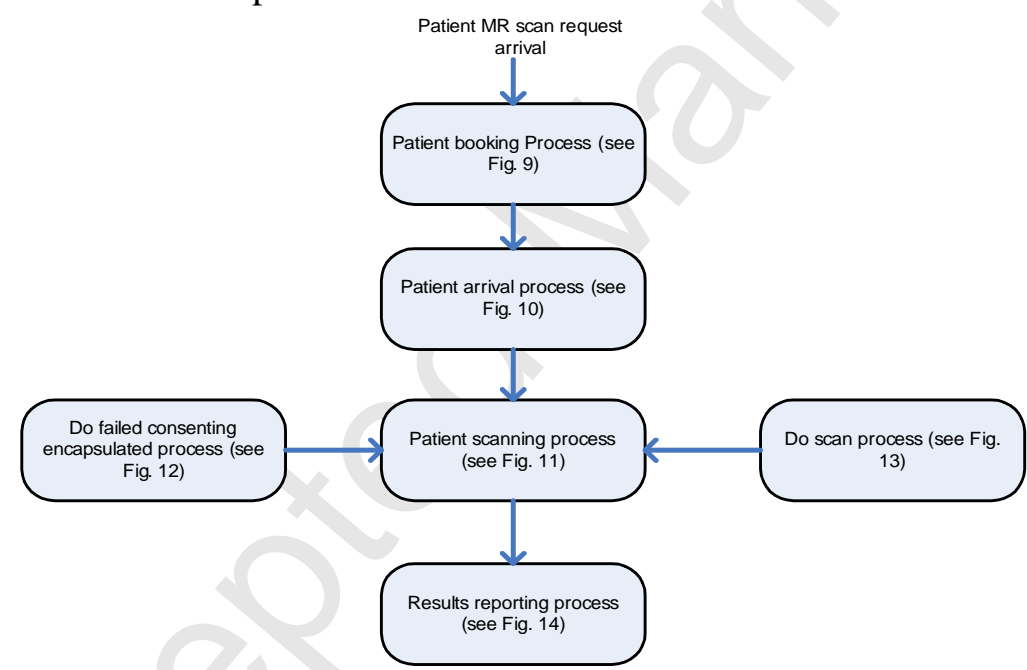

Figure 8: RAD models for the MR scanning process divided into patient booking process, patient arrival process, patient scanning process, and results reporting process

The MR scanning process starts when the patient scan request is received by the receptionist from doctors on the ward (for inpatients) or from doctors via an ebooking system (for outpatients). This begins the patient booking process, which is illustrated in Fig. 9, to allocate an appointment time to the patient for an MR scan. An outpatient MR scan request card is passed on to the receptionist dealing with the inpatient requests, who works simultaneously on other activities such as monitoring the e-booking system, generating and posting non-attendance letters and other activities, as shown in Fig. 4. All scan requests are then passed on to the radiologist. The radiologist decides whether or not the scan request has to be approved. The invalid MR scan requests are removed from booking and the referring doctors are notified. The scan requests accepted by the radiologist is given to the receptionist who books the inpatient paper-based card into the radiology information system (RIS) and outpatient scan requests are dealt with by the outpatient receptionist in the booking 
department. Figure 10 illustrates the patient arrival process for the actual MR scanning.

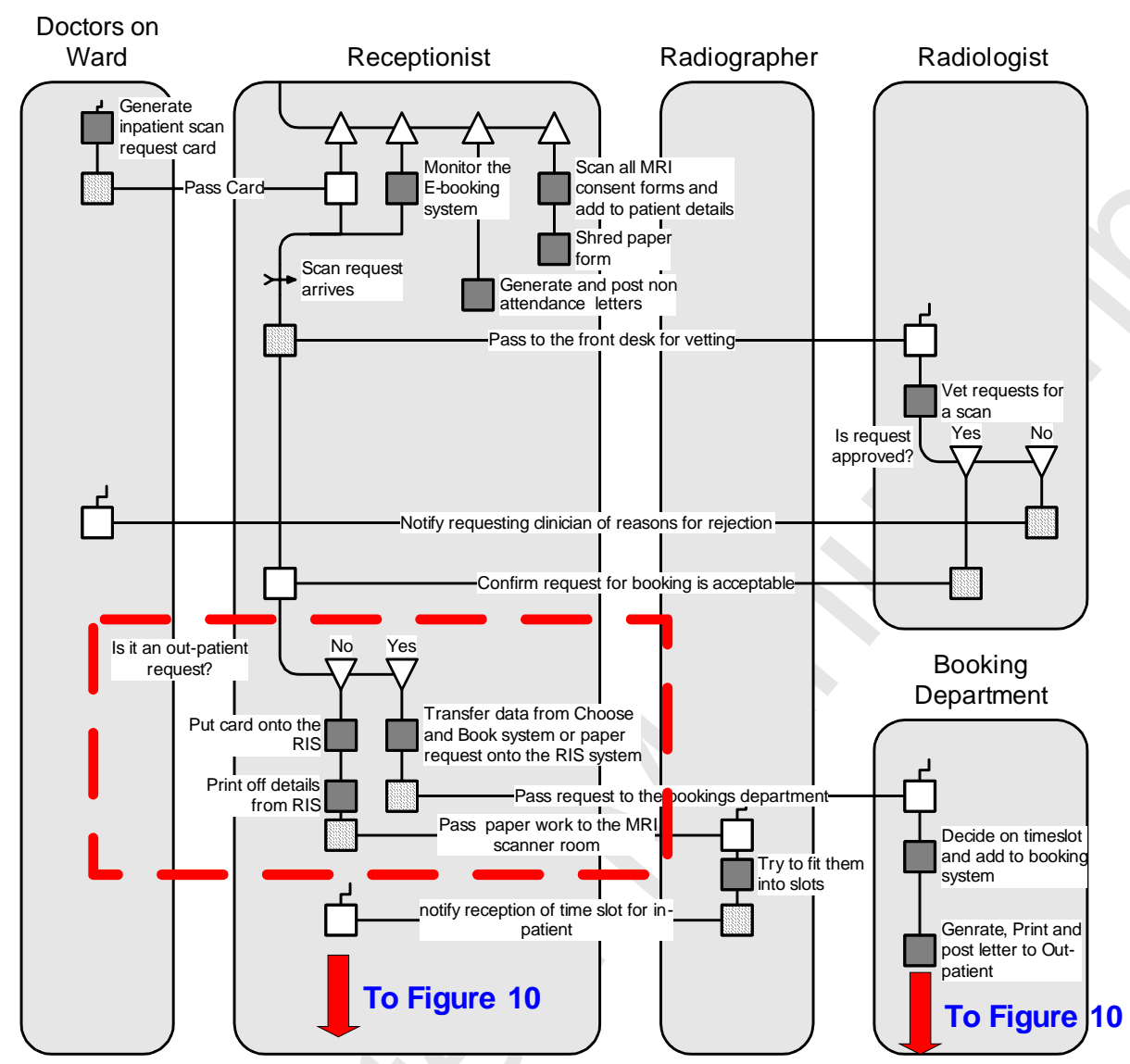

Figure 9: Patient booking process for MR scanning

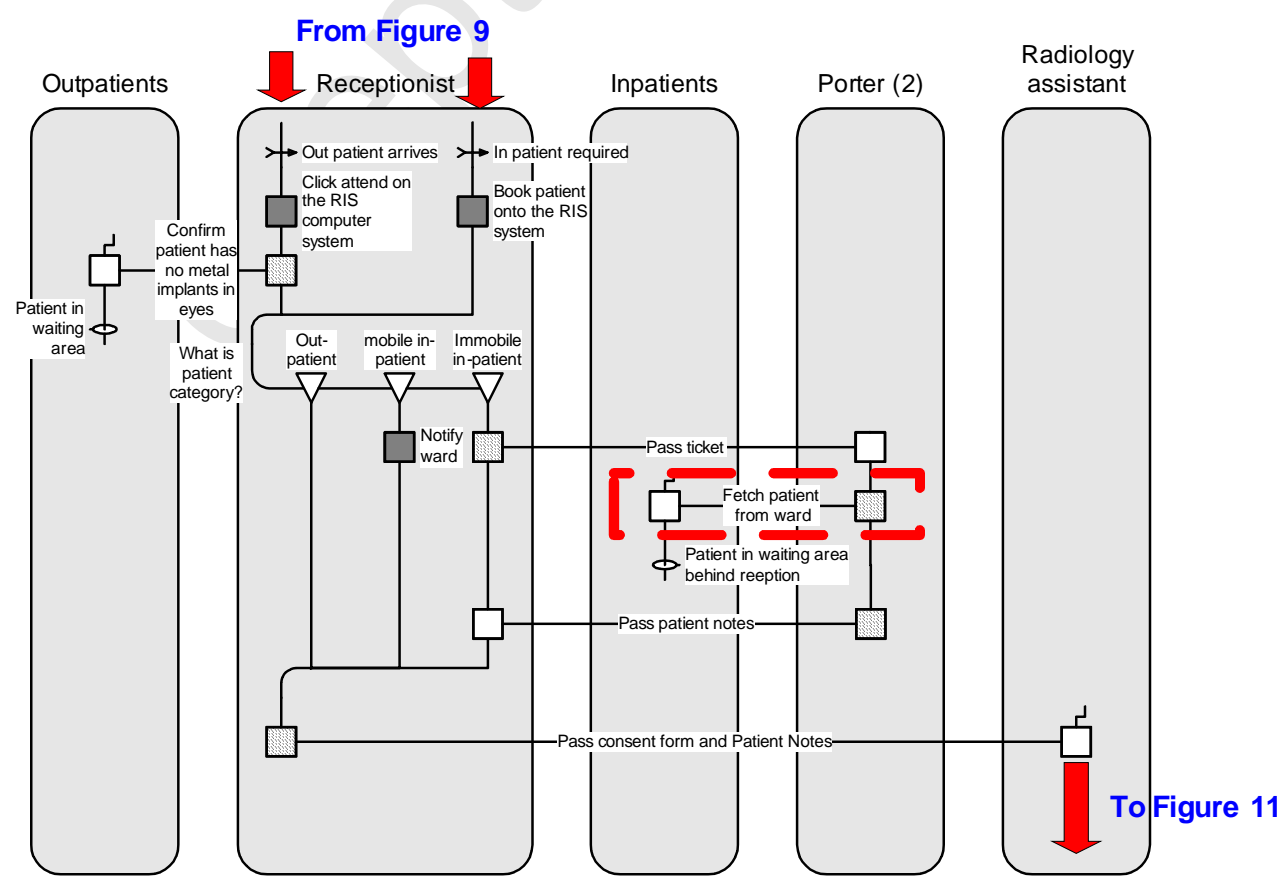

Figure 10: Patient arrival process for MR scanning 
Figure 11 shows the RAD diagram of the MR scanning procedure where the patient is handled by the radiology assistant and radiographers for scanning. Patients are taken from the MR/CT patient waiting area by the radiology assistant and about the patient is questioned as to the presence of metallic objects in their body.

Patients are advised to change into a hospital gown only after completing the consent form indicating that they have no metallic objects in their body. The failed consent procedure is illustrated in Fig. 12. If the patient is not sure, then X-ray scanning is used to check for metallic objects in the patient body.

After the patient has changed into the hospital gown and is ready for the MR scan, the radiographers are notified. The patient scan preparation by the radiology assistant is done while the previous patient is scanned by the radiographers. Patients are taken to the MRI room by the radiographers and adjustments to the MR scanners are done made. After this, the radiographer leaves the MR room and goes to the MR control room to do the scan. The encapsulated patient scanning process is represented by the RAD diagram shown in Fig. 13.

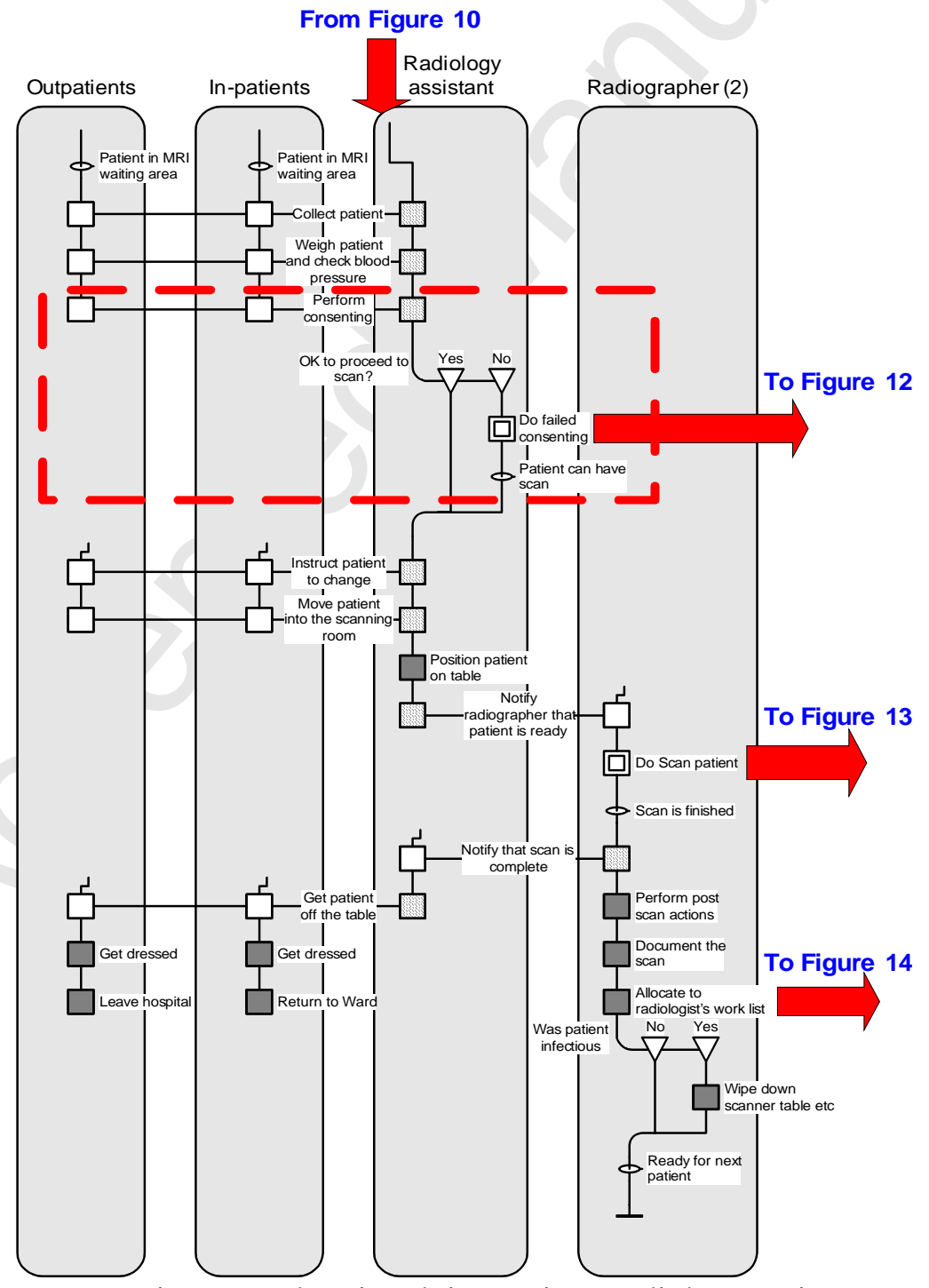

Figure 11: MR scanning procedure involving patient, radiology assistant, and two radiographers 


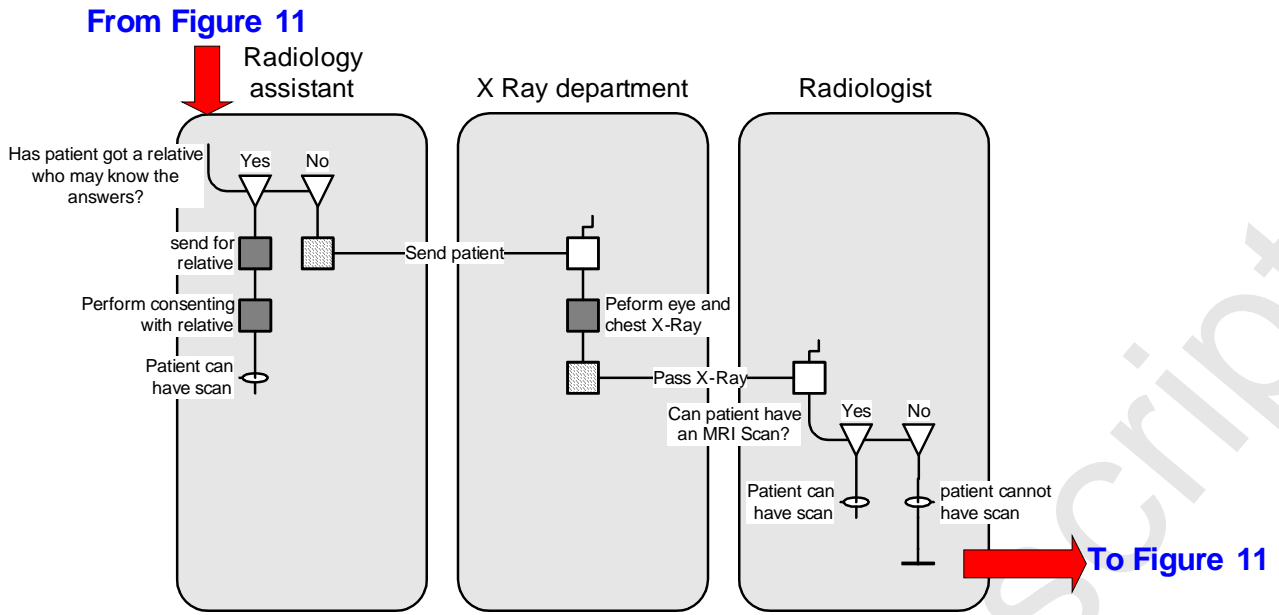

Figure 12: RAD showing the encapsulated failed consenting procedure

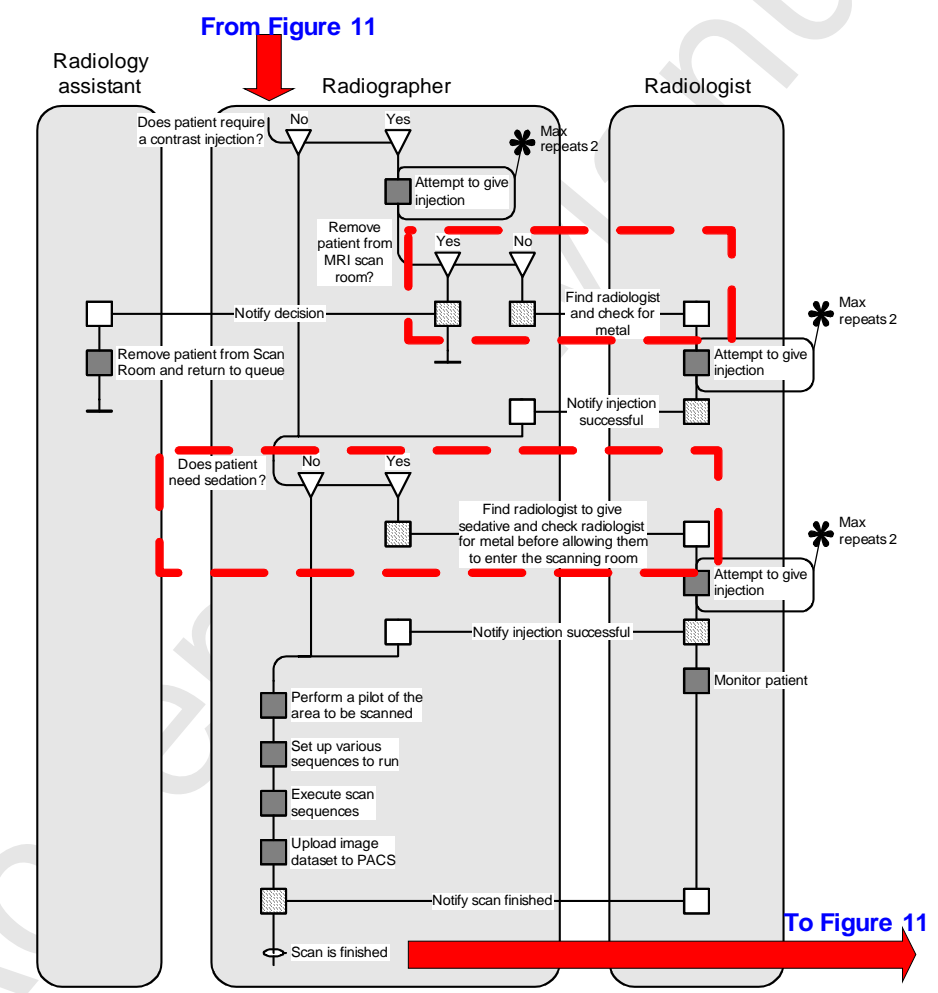

Figure 13: RAD showing the encapsulated patient scans process involving radiology assistant, radiographers, and radiologist

To produce quality scan images, some patients are given contrast or sedation injections. Radiographers are responsible for making this decision. Contrast injections are useful for scans requiring information about the flow of blood in the veins, here as sedation is required to calm down claustrophobic or child patients so that the MR scan can be performed smoothly. The activities performed by the radiographers and radiologist for sedated patients usually exceeds the duration of the appointment time. After the patient is properly positioned in the scanner, the radiographer sets up various scan sequences and other operations to run on their workstation. Execution of these 
activities results in scan images which are uploaded to a PACS and are allocated to a specialist radiologist. The patient is then released from the MRI room and preparations are made for the next patient. The scan is reviewed by the respective radiologist and the results are dictated onto the audio tape which is transcribed by the secretary (see Fig. 14). The diagnostic report on the patient MR scan is then passed on to the doctors requesting the patient scan.

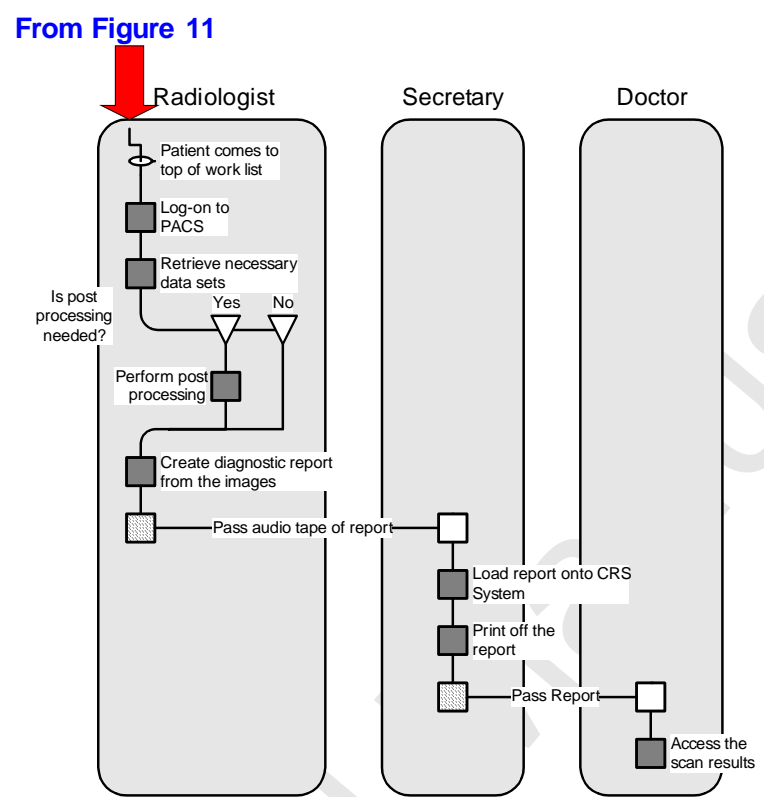

Figure 14: Results reporting process for MR scans

The MR scanning process is completed when the scanned images are reviewed and all related results are sent to the referring doctor. In brief, the patient scan requests are booked using the patient booking process. Depending upon the appointment date and time, patients arrive in the department for scanning and go through the patient arrival process. Subsequently, patients are scanned by the MR staff and the scan images are reviewed by the radiologists and reported to the referring doctor.

\section{DISCUSSION AND COMPARISON OF RAD-BASED MODELLING WITH VSM AND IDEFO}

Three workflow modelling methods: VSM, IDEF0, and RAD are compared and illustrated in Fig. 15. Figure 15 illustrates VSM and the IDEF0 model which is illustrated in Fig. 11 as RAD of the MR scanning procedure.

The developed RAD model can be utilized for a variety of applications including for radiology service delivery process improvements or process redesign, as discussed in the following section.

\section{RAD MODEL ANALYSIS FOR POTENTIAL AREAS OF IMPROVEMENT}

The RAD model of the MR scanning process can be used for a variety of applications, depending upon specific need and purpose. This section discusses the three major applications of the RAD model of the MR scanning process. 
The RAD-based process model can be used to provide information about the MR scanning service delivery process to radiology staff and to the radiology units of other hospitals for comparison and benchmarking. The RAD models represented are based on the set of standard notations on a computer and can be shared easily. RAD modelling notations encourage greater precision and clarity in understanding the process details, and are less likely to be misinterpreted by the person implementing the design in other radiology units. Hence, the RAD model can be used to document the existing service delivery process for sharing across multiple teams and hospitals.

RAD models of the MR scanning process having standard notations can be used to build a discrete event simulation model to analyse its performance. Based on the discrete event simulation model, the current performance of the MR scanning process can be determined and its performance can be studied. The discrete event simulation models based on the RAD model can increase the success rate of proposed changes because they can be evaluated before taking the risk and bearing the cost of implementation.

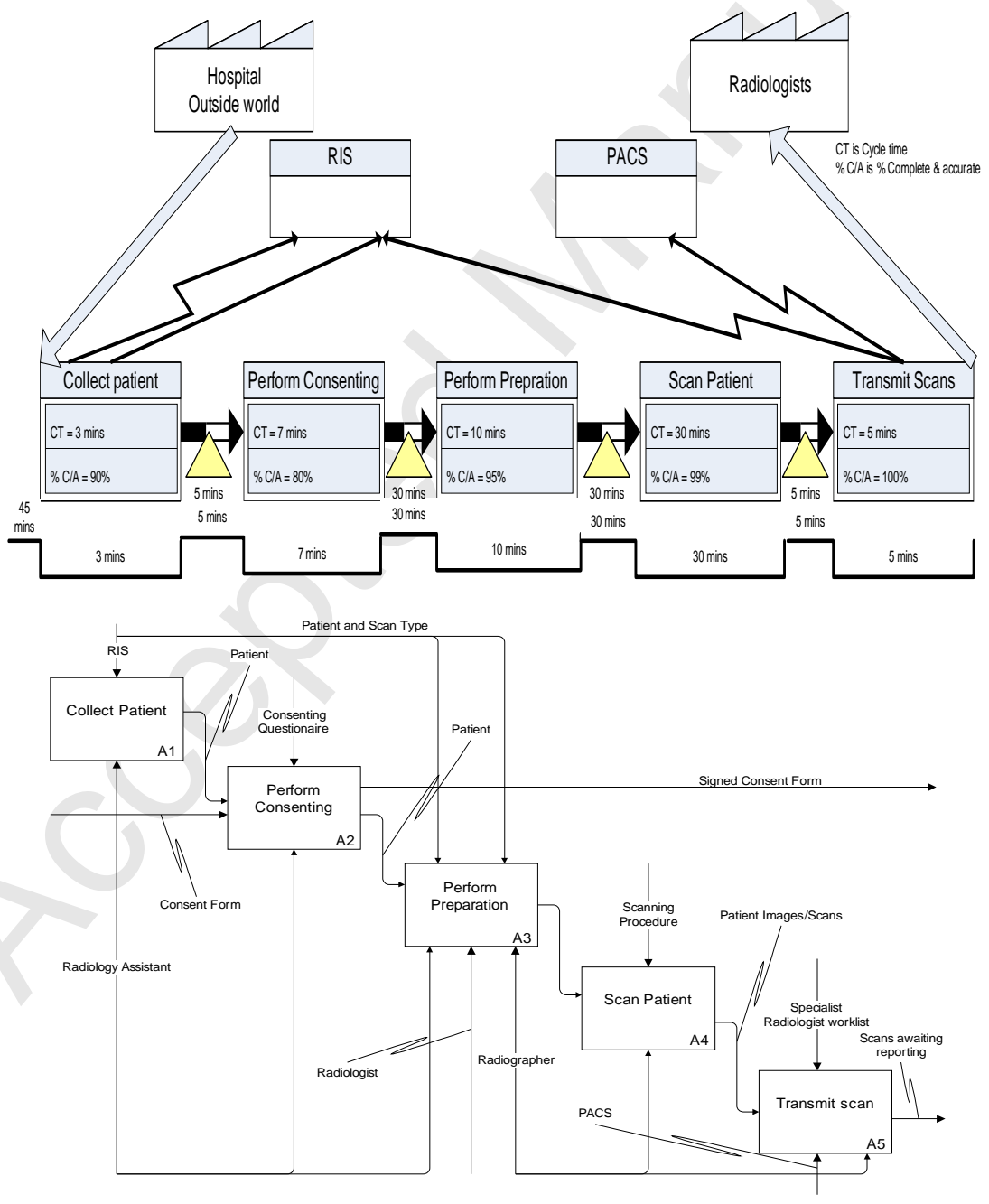

Figure 15: (a) Value stream mapping; and, (b) IDEF0 model for MR scanning procedure 
The major use of the RAD model of the MR scanning process is for suggesting improvements related to process redesign. Mapping of the existing MR scanning process reveals opportunities for process redesign by illustrating the activities, interactions, performed by staff in different roles in the service delivery process. Table 8 illustrates the identification of sensitive areas based on RAD architecture that have the potential to improve service delivery process. The sensitive areas can be identified based on: individual task complexity, long sequences of tasks, the decisionmaking process, cascading decisions made by staff in the same role, multiple or long interactions involved within the process. Table 8 also illustrates the impact of each of these complex RAD structures on the performance of the service delivery process.

Table 8: Identification of areas for improvement based on the complexity of service delivery elements

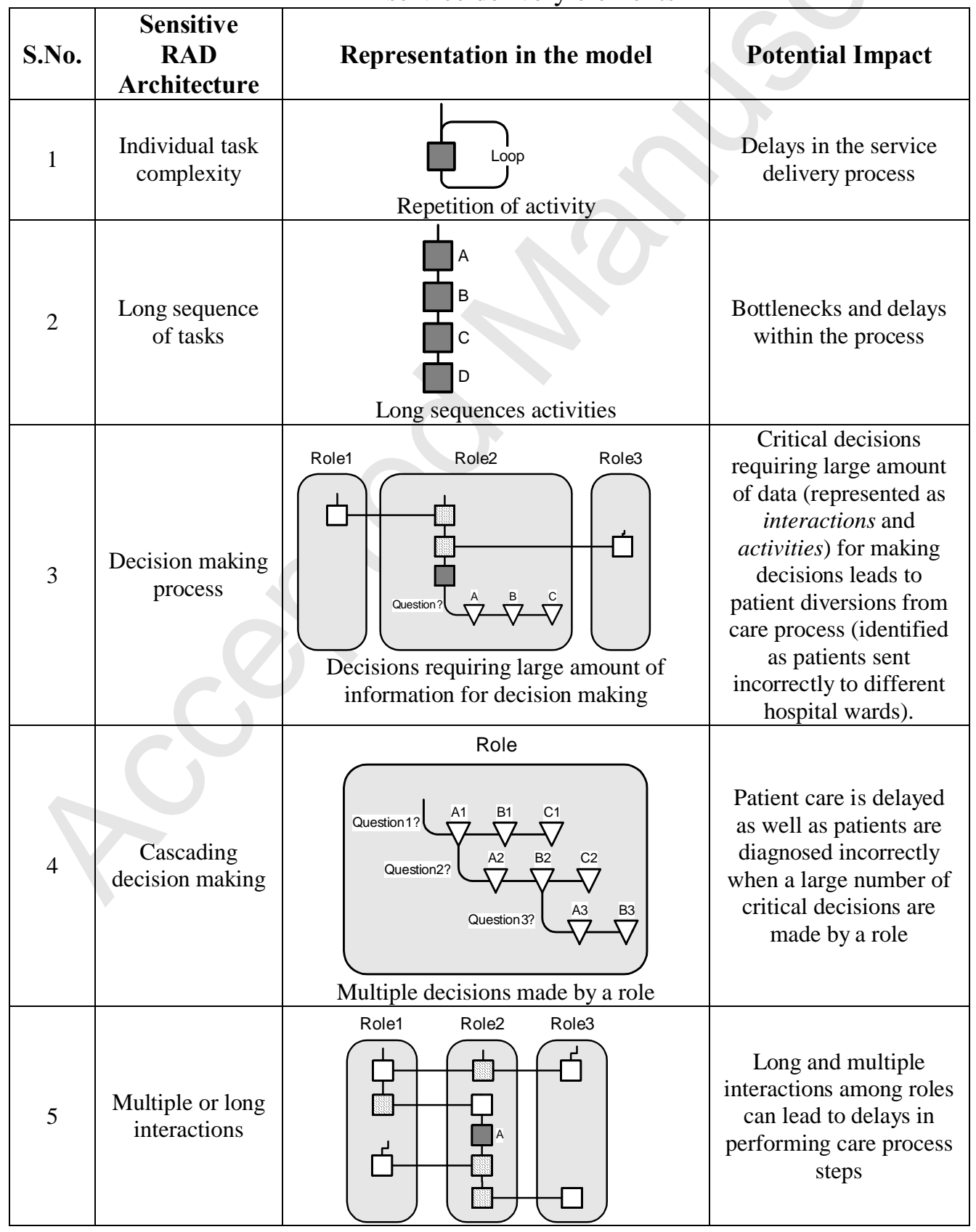


Based on the guidelines presented in Table 8, the RAD model of the MR scanning process (shown in Figs. 9-14) is used for suggesting improvements. The following areas of improvements were identified:

1. Develop an efficient patient booking system by eliminating redundant tasks: Our case study revealed, based on the sensitive RAD architecture (see decision making process in Table 8), that receptionist has to deal with both the paperbased card and the electronic booking systems (shown in Fig. 9). As a result, some redundant tasks are performed by the receptionist. These tasks are illustrated by the activities such as 'put card onto the RIS', 'print off details from RIS', 'transfer data from choose and book system or paper request onto RIS', and interactions such as 'pass paperwork to MRI scanner room'. Figure 9 illustrates these activities in the RAD model of the booking process (refer to RAD symbols in red rectangle in Fig. 9). Improvements in the current booking system can be realised by following the electronic booking system and taking steps to phase out the paper-based cards for booking.

2. Improve inpatient scanning: The inpatient requiring an MR scan is brought from the hospital ward by a porter, as illustrated in Fig. 10 ('fetch patient from ward'). This is identified as a time- consuming interaction (see long interactions lead to delays in Table 8). (refer RAD symbols in red rectangle in Fig. 10). As a result, inpatients may not arrive on time for their appointment. This interaction can be improved by better coordination among hospital wards and the radiology porters.

3. Improve inpatient consent by eliminating unnecessary delays: As can be seen in Table 8 , the procedure for obtaining consent can be a problem area (as shown in Fig. 11 by the interaction 'perform consent'). Often, this interaction can be time- consuming if the patient is unable to provide clear answers to the questionnaires. Our observation suggests that there may be several factors contributing to this delay. These include the confusion that surrounds some of the questions in the consent form; inadequate patient command of English; unavailability of appropriate translation services, and at times, to the critical condition of the patient. These problems can be reduced by informing the ward nurses who are taking care of the patient beforehand about the consent questions. The hospital ward nurses could then get the answers from the previous medical records of the inpatient. This, obviously, could not be done for outpatients, but it would, at least, save time for the inpatients.

4. Better patient preparation: Some of the patients booked for MR scanning require special pre-scan procedures such as sedation and contrast injections (shown in Fig. 13 as case refinements 'does patient require contrast injection' and 'does patient need sedation'). The radiographers or the radiology assistant has to locate a radiologist in order to monitor the patient's medical condition during such procedures (see interactions 'find radiologist and check for metal' and 'find radiologist to give sedative and check radiologist for metal before allowing them to enter scanning room' in Fig. 13). Providing the sedation/contrast injections and finding the radiologist for monitoring can lead to delays. This problem is identified based on the cascading decision making and individual task complexities represented in Table 8. The delay can be 
partly reduced by informing the radiologists beforehand about patients requiring sedation or contrast dye.

These applications of the RAD model can be useful for healthcare services for: designing and informing staff about the existing care-delivery process, developing discrete event simulation models and performance analysis, and suggesting service improvements based on a detailed view of the process. The significance of each of the service improvements can be evaluated based on discrete event simulation modelling, which will require quantitative time-related data about the process. The simulation model of the MR scanning process based on the RAD model can help identify the best possible improvement scenario.

The proposed RAD-based modelling also provides value to the realm of healthcare data analysis techniques that are used to understand process breakdowns. Traditional healthcare data analytical techniques, such as six sigma, multivariate statistical techniques, and data mining, incorporate performance metrics and time duration of process subcomponents in identifying bottlenecks in processes. On the other hand, the proposed RAD-based modelling methodology provides a detailed view of the process subcomponents and their interplay, based on procedural knowledge collected from staff interviews. The proposed approach also provides a set of RAD-based structural analysis guidelines and their potential impact on process performance (see Table 8). The data analytical models used for healthcare are mainly used for bottleneck analysis of a process; however for process redesign/re-engineering of healthcare service delivery process, a detailed process model is necessary. The proposed approach adds value to the existing data analysis techniques by allowing the process improvement analyst:

1. To identify the local causes of process bottlenecks: The data analysis model of the service delivery process, when developed with an adequate amount of quantitative data, will only highlight bottlenecks, for example long patient queues for scanning, etc. However, more detailed process-level information is needed to trace the causes of such bottlenecks. Thus, a complete analysis is needed and this requires a detailed process map.

2. To generate various ' what-if' scenarios for process improvement: The RAD model can be also utilized together with quantitative analytical techniques such as discrete event process simulations. This will result in simulating specific details such as resources (roles), activities (activities, interactions), decision- making, and parallel activities of the process for formulating and analysing various "whatif' scenarios.

3. To gather modelling requirements for data intensive simulation in healthcare:

Recently, Ryan and Heavey [35] have reviewed literature on using various process modelling methods for the requirement gathering phase of simulation. It is stated in the survey, that there is a lack of approaches based on process modelling methods to assist the requirement gathering phase, and this can consume twice as much resources as the coding phase of the simulation modelling. They suggest that the process modelling approach for the requirements phase should i) be able to capture detailed description of a discrete event system; ii) be less time consuming or have a low modelling burden and therefore be able to be used by non-specialists and iii) having good visualization capabilities. All of these aspects are present in the proposed modelling method.

4. To integrate process mapping with quantitative simulation modelling methods for process redesign and bottleneck analysis: 
A survey by Hulpic [36] states that less than $10 \%$ of the process improvement studies involved any kind of simulation modelling tools. The main reasons for the lower number of applications of simulation modelling tools in process improvement are: [37-38]: (a) lack of interface- integrating simulation software and process modelling approaches, (b) the extensive simulation modelling expertise necessary to build simulation models, (c) the use of domain expert and simulation analysts while modelling a process. The review of process mapping and DES modelling approaches suggests that it is inappropriate to use any of these approaches alone for process improvements. The use of process modelling alone lacks the ability to analyse and predict the behaviour of processes in case of process change. On the other hand, simulation models utilizing flow diagrams fail to capture the inherent complexity of the service delivery process. The information provided by both of these methods needs to be integrated for a detailed analysis of the processes. Although the aim of this paper was to propose a RAD-based process mapping methodology for process redesign, but, building a simulation model from RAD will be the topic for future research.

\section{CONCLUSION}

This paper deals with the quick and reliable development of RAD to improve service delivery process in a radiology department. The proposed RAD development methodology considers qualitative interviews of radiology staff. The interviews are recorded and then transcribed. A mark-up tool is developed to mark related concepts in the interview transcripts. The concepts are matched using a matrix-based relationship builder using simple tables. These relationships are then exported to Microsoft Visio to draw a RAD of the system. The developed RAD is a flexible approach that can be modified and edited for inconsistencies. The resulting RAD models can be utilized for process improvement for explaining the design of the process to others, and can also be applied to develop simulation models of the process. The proposed methodology is applied to the radiology services of a large hospital to reduce the unwarranted delays in the MR scanning process leading to better, and more efficient provision of specialised care to patients.

Although the proposed RAD-based methodology has been applied to radiology services in this paper, it can also be used for modelling in several other hospital departments. It can be extended to model various complex patient-care pathways which involve several hospital departments, with their specialised clinical expertise. This could result in hospital models which can be used as a standard operating procedure in cases requiring multidisciplinary care and treatment. Very useful simulation models can also be developed from the RAD models of the process.

\section{ACKNOWLEDGEMENT:}

The authors wish to gratefully acknowledge the help of anonymous reviewers for constructive comments and Dr. Madeleine Strong Cincotta in the final language editing of this paper.

\section{References:}

1. Reiner, B., Siegel, E., Carrino, J. A., Workflow optimization: current trends and future directions, Journal of Digital Imaging, 15(3), (2002), pp. 141- 152.

2. Ploeg, J. Identifying the best research design to fit the question. Part 2: qualitative designs, Evidence Based Nursing, 2 (1999), pp. 36-37. 
3. Rosenhead, J. Rational analysis for a problematic world: problem structuring methods for complexity, uncertainty and conflict, John Wiley, (1989), ISBN 0471-92285-4.

4. Lehaney, B., Paul, R., The Use of Soft Systems Methodology in the Development of a Simulation of Out-patient Services at Watford General Hospital, Journal of the Operational Society, 47, (1996), pp. 864-870.

5. Robinson, S., Soft with a hard centre: discrete-event simulation in facilitation. Journal of the Operational Research Society, 52, (2001), pp: 905-915.

6. Mingers, J., Rosenhead, J., Problem structuring methods in action" European Journal of Operational Research, 152, (2004)pp: 530-554.

7. Kotiadis, K., Mingers, J. Combining PSMs with hard OR methods: the philosophical and practical challenges, Journal of the Operational Research Society, 57, (2006), pp. 856-867.

8. Crabbe JP, Frank CL, Nye WW. Improving report turnaround time: an integrated method using data from a radiology information system," American Journal for Roentgenology, 163, (1994), pp. 1503-1507.

9. Rother, M., Shook, J., Learning to See - Value-stream Mapping to Create Value and Eliminate Muda, Lean Enterprise Institute, (2003), ISBN: 9780966784305.

10. Kudyba S. Healthcare informatics: increasing efficiency and productivity. New York: Taylor Francis, (2010).

11. Bar-Or A, Keren D, Schuster A, Wolff R. Hierarchical decision tree induction in distributed genomic databases. IEEE Trans Knowl Data Eng, 17(8), (2005), pp. 1138-1151.

12. Stephan Kudyba and Thomas Gregorio Identifying factors that impact patient length of stay metrics for healthcare providers with advanced analytics, Health Informatics Journal, 16 (4), (2010), pp. 235-245.

13. Christopher L. Meli, Ibrahim Khalil, Zahir Tari, Load-sensitive dynamic workflow re-orchestration and optimisation for faster patient healthcare, Computer Methods and Programs in Biomedicine, Volume 113 (1), (2014), pp. $1-14$.

14. Fernando C. Coelli, Rodrigo B. Ferreira, Renan Moritz V.R. Almeida, Wagner Coelho A. Pereira, Computer simulation and discrete-event models in the analysis of a mammography clinic patient flow, Computer Methods and Programs in Biomedicine, 87(3), (2007), pp. 201-207.

15. Duguay, Christine, Chetouane, Fatah, Modeling and Improving Emergency Department Systems using Discrete Event Simulation, Simulation, 83(4), (2007), pp. 311-320.

16. Molema, J. J. W., Groothuis, S., Baars, I. J., Kleinschiphorst, M., Leers, E. G. E., Hasman, A., and van Merode, G. G., "Healthcare system design and parttime working doctors" Health Care Management Science, 10(4), (2007), pp. 365-371.

17. VanBerkel, Peter T., Blake, John T., A comprehensive simulation for wait time reduction and capacity planning applied in general surgery, Health Care Management Science, 10(4), (2007), pp. 373-385.

18. Jeffrey S. Barrett, Bhuvana Jayaraman, Dimple Patel, Jeffrey M. Skolnik, A, SAS-based solution to evaluate study design efficiency of phase I pediatric oncology trials via discrete event simulation, Computer Methods and Programs in Biomedicine, 90(3), (2008), pp. 240-250. 
19. Shadbolt, N., Milton, N., From Knowledge Engineering to Knowledge Management, British Journal of Management, 10, (1999), pp. 309-322.

20. Miller, M. J., Ferrin,D. M., Shahi, N., LaVecchia, R., Using RFID Technologies to Capture Simulation Data in a Hospital Emergency Department, Proceedings of the $40^{\text {th }}$ Conference on Winter Simulation, (2008), pp. 1637-1644.

21. White K.P., Jr., A Survey of Data Resources for Simulating Patient Flows in Healthcare Delivery Systems, In Proceedings of the 2005 Winter Simulation Conference, (2005), pp. 926 - 935.

22. White, K.P., Jr.. "Area-Wide Ambulance Diversions: Data Resources for Simulation Modeling" In Proceedings of the 2005 Winter Simulation Conference, (2005), Ed. M.E Kuhl, N.M. Steiger, F.B. Armstrong, and J.A. Joines, Piscataway, New Jersey: Institute of Electrical and Electronics Engineers.

23. Stevens, W., Myers, G., Constantine, L. "Structured Design", IBM Systems Journal, 13(2), (1974), pp. 115-139.

24. Stead, W.W. \& Lin, H.S. (Eds), "Computational Technology for Effective Health Care: Immediate Steps and Strategic Directions," National Research Council, Washington, DC, (2009), Available on the web at: http://www.nap.edu/catalog/12572.html.

25. Staccini, P., Joubert, M., Quaranta, J.F., and Fieschi, M. "Mapping care processes within a hospital: from theory to a web-based proposal merging enterprise modelling and ISO normative principles" International Journal of Medical Informatics, 74(2-4), (2005), pp. 335-344

26. Reijers, Hajo A., Mendling, Jan, "A Study into the Factors that Influence the Understandability of Business Process Models" IEEE Transactions on Systems, Man, And Cybernetics - Part A, 41(3), (2011), pp.449-462.

27. Sun, S.X.; Qingtian Zeng; Huaiqing Wang "Process-Mining-Based Workflow Model Fragmentation for Distributed Execution," IEEE Transactions on Systems, Man, And Cybernetics - Part A, 41(2), (2011), pp.294-310.

28. McInnes, A.I., Eames, B.K., Grover, R. "Formalizing Functional Flow Block Diagrams Using Process Algebra and Metamodels," IEEE Transactions on Systems, Man, And Cybernetics - Part A, 41(1), (2011), pp.34-49.

29. Lakin, R. "BPR enabling software for the financial service industry", Management Services, 40(3), (1996), pp.18-20.

30. Charles C.H. Liu, Chia-Huang Chang, Mu-Chun Su, Hsueh-Ting Chu, ShengHui Hung, Jau-Min Wong, Pa-Chun Wang "RFID-initiated workflow control to facilitate patient safety and utilization efficiency in operation theatre," Computer Methods and Programs in Biomedicine, 104(3), (2011), pp. 435442.

31. Aguilar-Savén, R. S., "Business process modelling: Review and framework", International Journal of Production Economics, 90(2), (2004), pp. 129-149.

32. Naoki Ohboshia, Hisayuki Masuib, Yahiko Kambayashic, Takashi Takahashia, "A study of medical emergency workflow" Computer Methods and Programs in Biomedicine, 55(3), (1998), pp. 177-190.

33. Ould, M.A., "Business processes: modelling and analysis for re-engineering and improvement." Chichester; New York: Wiley \& Sons, (1995).

34. Ould, M.A., "Business Process Management: A Rigorous Approach", Meghan-Kiffer Press, (2005). 
35. Ryan, J., Heavey, C., "Process modeling for simulation" Computers in Industry, 57(5), (2006), pp: 437 - 450.

36. Hlupic, V., "Business Process Re-engineering and Simulation: Bridging the Gap". In Proceedings of the European Simulation Multiconference (ESM'98), Ed. by Zobel R. and Moeller D., SCS, (1998), pp: 641-645.

37. Gladwin, B. and Tumay, K., "Modelling business processes with simulation tools", In Proceedings of the 1994 Winter Simulation Conference, (1994), pp: 114-121.

38. Lingineni, M., Caraway B., Benjamin P. and Mayer R. "A tutorial on PROSIM: A knowledge-based simulation model design". In Proceedings of the 1995 Winter Simulation Conference, (1995), pp: 408-412.

39. Shukla, N, John Keast, Darek Ceglarek, "Modelling variations in hospital service delivery based on real time locating information" Applied Mathematical Modelling, 38(3), (2014), pp. 878-893.

40. Shukla, N., Kiridena, S., Mishra, N. "Reducing unwarranted variation in healthcare service delivery systems: key issues, research challenges and potential solutions" 26th ANZAM Conference 2012

41. Shukla, Nagesh, Keast, John, Ceglarek, Sudi L. and Ceglarek, Dariusz "Role activity diagram-based workflow modelling of imaging service delivery process in radiology" In: The 7th International Conference on Manufacturing Research (ICMR' 09), University of Warwick, Coventry, U.K., Sep 8-10, 2009. Published in: Proceedings of the 7th International Conference on Manufacturing Research (ICMR' 09) pp. 283-291. 


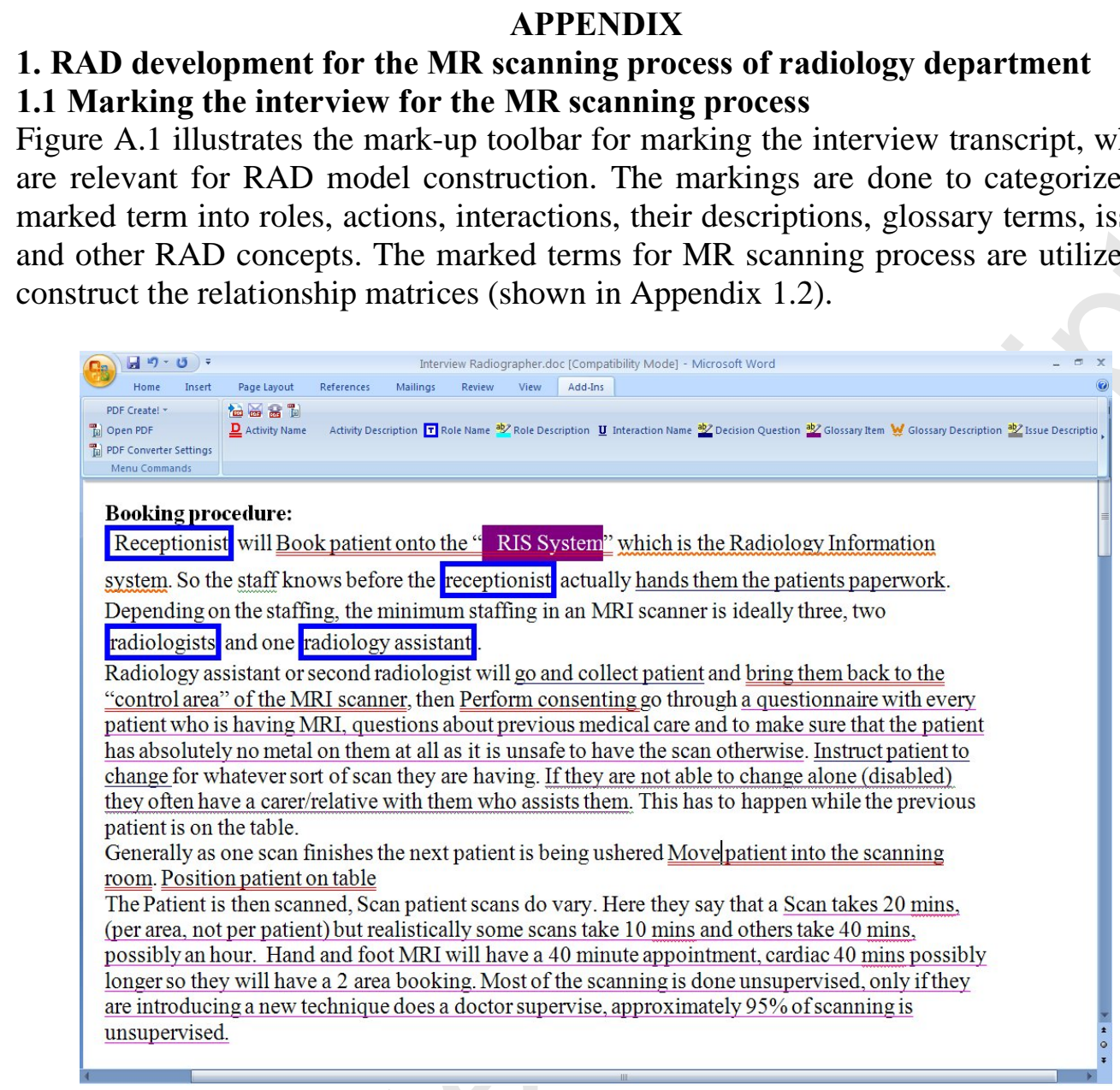

Figure A.1: Microsoft Word mark-up tool for marking the interview transcript

\subsection{Relationship builder interface for relating the marked concepts}

The marked term obtained from marking the interview transcript is utilized to construct the AT matrix for MR scanning process. The interview terms marked as action represents rows of the AT matrix. The column of AT matrix classifies the action term into activity, state, trigger, start role, case refinement, part refinement encapsulated process. Step 2 of Section 3.1 further details the process of creation of the relationship matrices.

The AR matrix is constructed for MR scanning process by making the terms marked as actions as its rows and term marked as roles as its columns. Hence, the $\mathbf{A R}$ matrix relates the actions with its respective roles in MR scanning process. Step 2 of Section 3.1 further details the process of creation of the relationship matrices. 


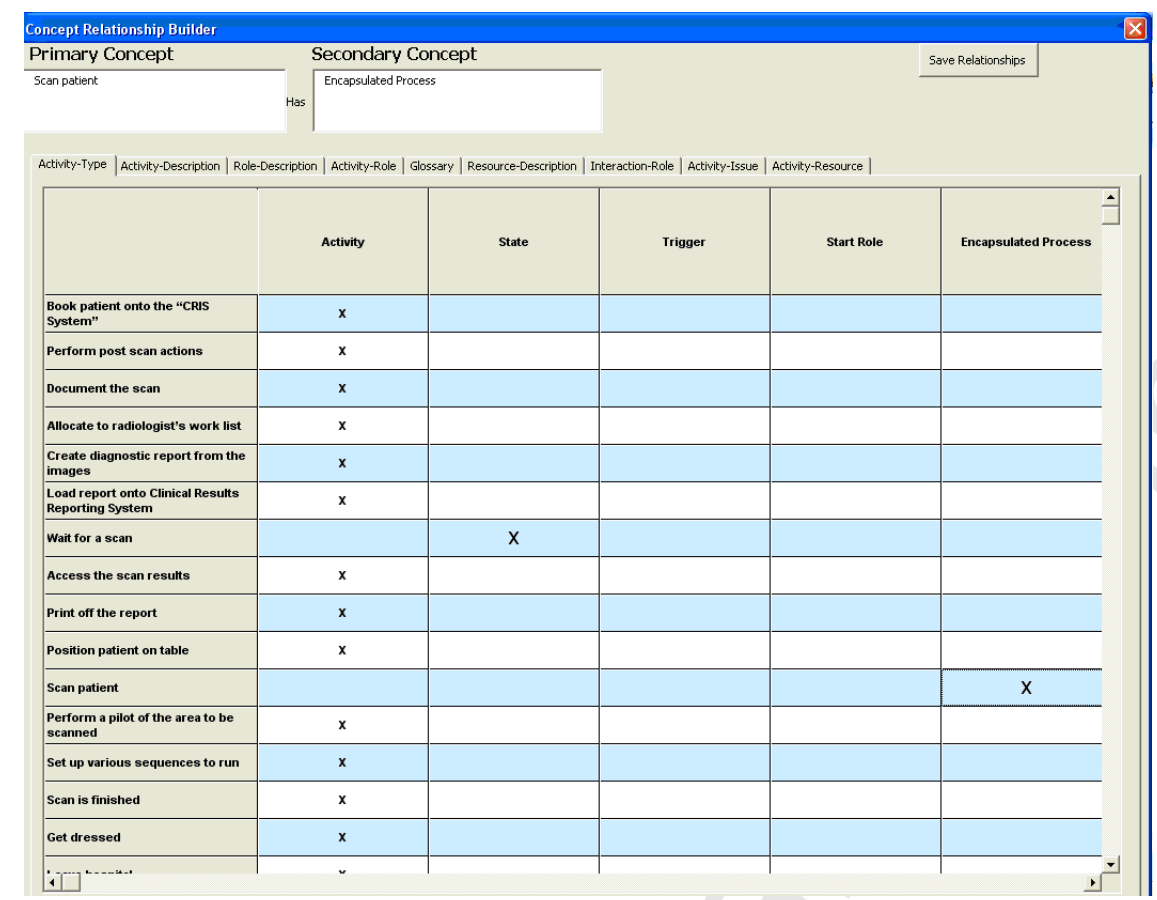

Figure A.2: AT matrix in the relationship builder interface for the MR scanning process

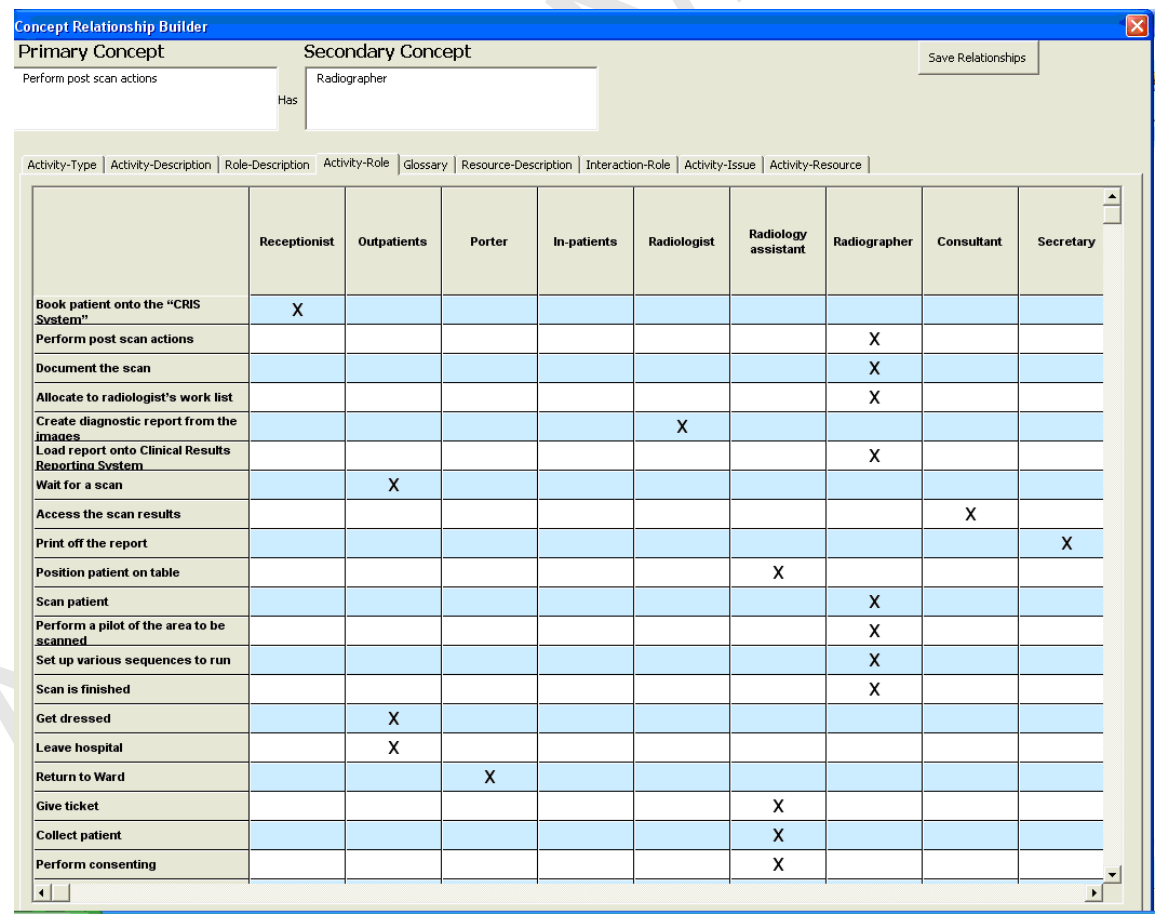

Figure A.3: AR matrix in relationship builder interface for the MR scanning process

The IR matrix is derived by putting the interactions term marked in the interview term as its rows. The column of the IR matrix defines the role term marked in the interview term. The values corresponding to a row and column established the relation between them. Step 2 of Section 3.1 further details the process of creation of the relationship matrices. 


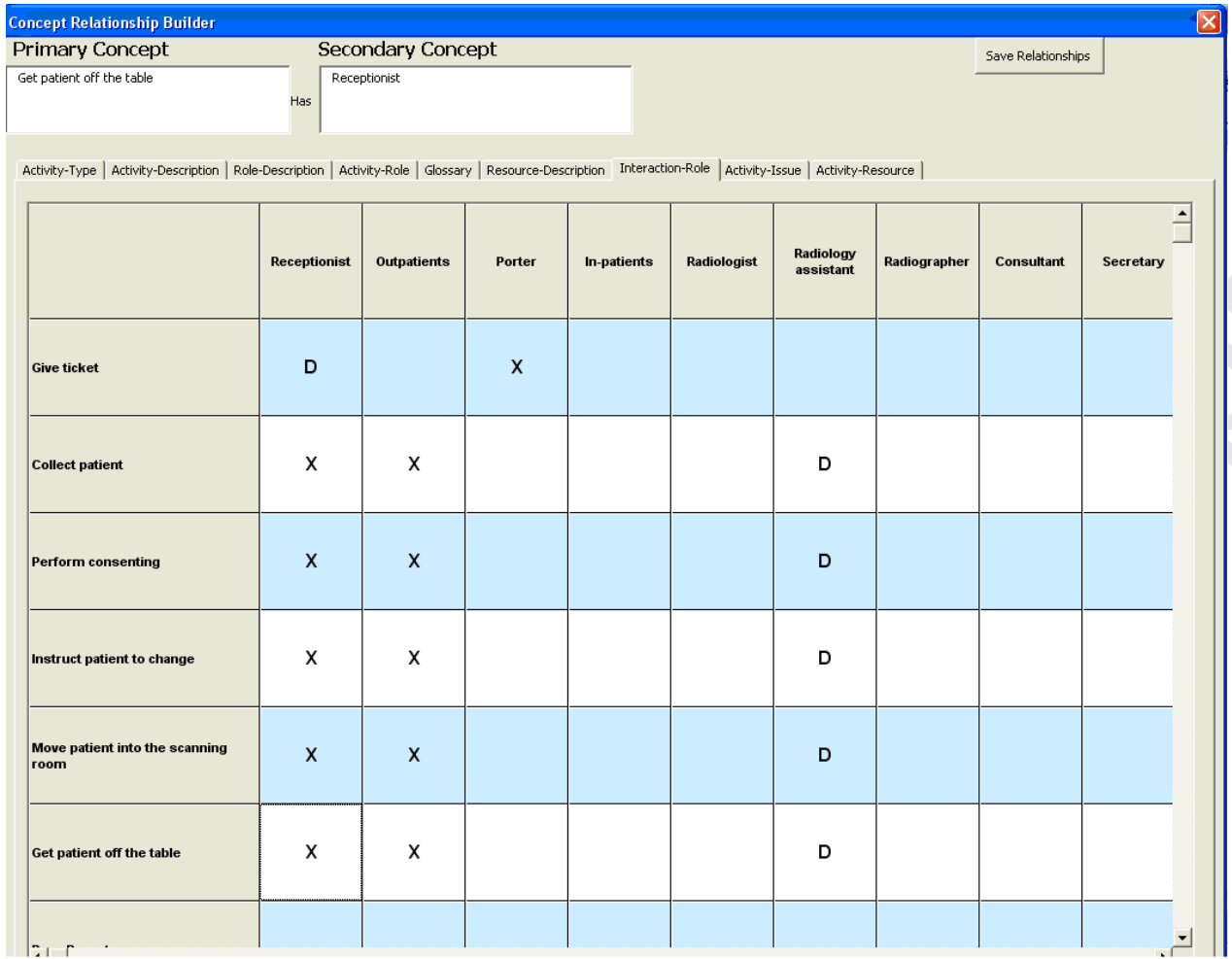

Figure A.4: IR matrix in relationship builder interface for the MR scanning process 
The highlights of the proposed study are -

- Development of systematic knowledge acquisition and knowledge aggregation methodology based on staff interviews;

- Use of RAD based process models for representing process knowledge aggregated from staff interviews;

- Analysis of sensitive RAD structures for process issues identification; and,

- Application of proposed methodology to a real case study from radiology department of a large hospital. 